\title{
ARE FOREIGN OWNED FIRMS MORE LIKELY TO PAY BRIBES THAN DOMESTIC ONES? EVIDENCE FROM EMERGING MARKETS
}

\begin{abstract}
An extensive literature exists on the adverse effects of corruption on inward FDI and the impact this may have on economic development but the reverse causality has not been fully explored. Legislation in the US and the EU prohibits firms from engaging in corrupt practices in foreign countries and this suggests that foreign owned firms might be less likely to pay bribes. However, such legislation may be ineffective because foreign firms have to adapt to local market conditions or risk being uncompetitive. Using firm level data for 41 emerging countries, a probit model estimates the probability that a firm pays bribes. To allow for possible endogeneity this probit analysis is repeated with an instrument to proxy for endogenous foreign ownership. Then, a propensity score matching technique tests for differences in the propensity to pay bribes by domestic and foreign firms. The paper finds that no difference is the behaviour of foreign owned and domestic firms with respect to corrupt practices. Results are robust to different levels of foreign ownership and support the view that foreign owned firms adapt to local practices and are neither more nor less likely to pay bribes than comparable domestic firms. The paper finds that other variables including bureaucracy, government contracts and perceived difficulties with civil society (legal and political) do have statistically significant effects on increasing bribery and that some others, such as per capita GDP, tend to reduce bribery. The study concludes that there is no evidence that foreign ownership, after investment has occurred, tends to reduce bribery but it does support the view that foreign owned firms adopt local behavioural norms.
\end{abstract}

KEYWORDS Inward FDI, Corruption, Emerging markets, Propensity score matching

FUNDING This research did not receive any specific grant from funding agencies in the public, commercial, or not-for-profit sectors. 


\section{HIGHLIGHTS}

- Home country legislation prohibits corrupt practices for inward FDI firms but in some environments this makes them uncompetitive with host country firms

- The propensity to engage in corrupt practices in emerging markets is the same for foreign and domestic firms if it is necessary to circumvent cumbersome bureaucracy

- This result is robust to the degree of foreign ownership of a firm

- Propensity score matching provides an unbiased method of comparing sub-groups 


\section{ARE FOREIGN OWNED FIRMS MORE LIKELY TO PAY BRIBES THAN DOMESTIC ONES? EVIDENCE FROM EMERGING MARKETS}

\section{Introduction}

Corruption has been an issue of considerable importance in both the international business and economic development literatures for some time. This interest is not surprising as corruption can be both a barrier to investment (Mauro, 1995) and lead to higher costs to the firm (Shleifer and Vishny, 1993). However, the nature of the relationship between corruption and development has been questioned. The established view is that there is an inverse relationship between corruption and economic growth (Truex, 2011) although this may not be the case where institutions are weak (Méon and Weill, 2010).

The literature on international business has focused on the deterrent effects of bribery on inward investment. There have been only a few studies of the effects of foreign owned firms on bribery and those that do exist have tended to focus on a single country. The literature on the determinants of corruption comprises a larger body of work but foreign ownership is considered as a possible determinant only in a small number of studies, typically as a dummy variable and as one of several control variables. Thus, the major contribution of the paper is to provide a more focussed examination of the role of foreign owned firms in bribery practices than exists in either the international business or corruption literature. This study does not consider the role of foreign ownership in isolation but also focuses on bureaucracy, bidding for government contracts and polity (political instability, crime, corruption and the courts) in determining corruption. These, too, have been considered elsewhere in the literature but this study adopts a more focused approach to them. In keeping with the literature on corruption this study uses firm level data for a number of countries. Firm level data comes with the problem of firm heterogeneity which can create a risk of sample selection bias. To address these heterogeneity problems a matching approach is used. As far as the authors are aware this study is the first to apply inverse probability weighted regression adjustment (IPWRA) techniques to the determinants of corruption. 
One aspect of the recent literature has focused on the deterrent effect of bribery on inward investment particularly in emerging market countries but also more generally. Two important ideas that arise from this motivate this paper. The first concerns the question of whether foreign owned firms tend to reduce corruption in host countries or simply find themselves compelled to adopt local standards and practices. The introduction of legal requirements in both the US and the European Union to refrain from corruption in foreign countries provides a clear motive for suspecting that the participation of foreign owned firms in the host country might reduce corruption levels. It is clearly the case that paying bribes might expose them to prosecution in their home country and, hence, alter their behaviour. But the opposite may be the case as no matter how worthy home country legislation might be foreign owned firms face the reality of having to operate according to local standards and practices or risk being uncompetitive. Despite the risk of home country recrimination it is argued that they have little choice other than to compete with local firms even if this involves paying bribes. The second strand of recent research considers that whilst official corruption is never the first best solution, it may be better than nothing where a particularly obstructive and cumbersome bureaucracy is in place. This reasoning is not the main focus of this study but we do consider the likelihood that corruption and cumbersome bureaucracy are related.

This study does not set out to provide a comprehensive analysis of the determinants of bribery. Its focus is on whether the fact that firms are foreign owned affects bribery or not. Nonetheless, any analysis of the role of foreign ownership affects bribery in host markets only makes sense in the context of a wider model of its determinants. Based on existing literature the study also considers a number of potential firm-level determinants of bribery. These include government contracts, bureaucracy, perceived legal and political obstacles and indicators of firm competitiveness. A number of country-level determinants are also considered. These include regulatory efficiency, per capita GDP and natural resource rents (as a percentage of GDP). The findings that many of these variables do indeed have statistically significant effects on bribery, and that foreign firms tend to adapt to rather than change local behavioural norms, has obvious policy implications. 
This is clearly of interest to policy makers, who are aware of the adverse effects of corruption in international firms on economic growth in emerging and newly industrialised economies. The key question from the policy perspective is whether legislation in home countries has been effective in making foreign firms less likely to pay bribes than domestic ones. It is also of interest to managers of firms from those countries who have introduced legal sanctions at home against firms that engage in corruption in other countries. These firms face a potential dilemma. On one hand, if the legislation is enforced, they risk sanctions in their home country, while on the other hand if corruption is expected in a particular host country it may not be possible for their affiliates or subsidiaries to compete effectively abroad. Therefore, understanding the typical behaviour of other foreign firms in this situation is of value for the development of appropriate overseas business strategies.

Whilst is it often asserted that bribery is a particularly acute problem in emerging market countries, this study does not address whether this is or is not an accurate stereotype. The sample is drawn from emerging and newly industrialised markets because that is where corruption is believed to be an important issue although this is not necessarily the case. However, the sample raises two further issues with respect to the quality of governance and level of development. It is important to note that the sample does not include China or India. This is not because these countries are not of major importance but firm level data are limited and neither is included in the World Bank Enterprise Survey, which is the source of data used here.

The paper proceeds as follows. Section 2 discusses the literature on corruption in the context of international business and economic development and a number of testable hypotheses are developed. Section 3 describes the data and methods used. The next two sections report the results of the probit estimation and propensity score matching followed by a discussion and section 6 concludes.

\section{Review of literature and hypothesis development}

This study concerns two related and overlapping strands of literature. Its focus is on the role of affiliates of foreign firms. The literature on FDI and corruption has been dominated by analysis of the 
deterrent effects of corruption on inward FDI (causality: corruption to FDI). An under researched aspect of the literature which has only started to be addressed more recently is the effects of foreign ownership on corruption (causality: foreign ownership to corruption). This paper is one of the few attempts in the FDI literature to assess whether foreign owned firms offer benefits to host countries in the form of reduced corruption. It is not, as with Rose Ackerman (2002), an analysis of whether foreign firms should be obliged to reduce corruption but an empirical assessment of whether they do in reality.

The literature from the perspective of the costs and benefits of inward FDI inevitably overlaps with the literature on the determinants of corruption more generally. A small number of studies within the determinants of corruption literature have analysed the effects of foreign ownership (usually in the form of a dummy variable) on corruption, typically finding no statistically significant effect. This study's focus on foreign ownership as a potential determinant allows a more thorough examination of the role of foreign ownership in relation to other potential determinants of corruption. Firm level studies such as this have become increasingly used in the determinants of corruption literature, typically with probit (which this study uses) or logit regression models. However, problems of firm heterogeneity have long been recognised as an issue with micro level data. To address such issues a matching approach is introduced. In addition, we use Inverse Probability Weighted Regression Analysis (IPWRA), a method that to the best of our knowledge has not previously been applied in studies of the determinants of corruption. The results presented here show that it produces clear conclusions from the fog of firm heterogeneity.

Evidence that corruption has had an adverse effect on both investment and economic growth has existed in the economic development literature for some time. For example, in a cross country study Mauro (1995) found that corruption adversely affected both investment and per capital GDP growth. The literature more specifically related to foreign owned firms is more recent but is still well established. Wei (2000) examined the relationship between FDI and corruption using bilateral country level data and found that corruption had a negative effect on direct investment similar to an increase in the tax rate. A country level analysis of FDI by Habib and Zurawicki (2001) found a statistically 
significant negative impact of corruption on FDI inflows. In a separate study of FDI inflows the same authors found that corruption was a significant and serious obstacle to inward FDI (Habib and Zurawicki, 2002). Globerman and Shapiro (2002) examined the relationship between the quality of governance and FDI flows (inward and outward) at the country level and found good governance to have a significant positive effect on FDI flows. Similarly, in a study of US outward investment good governance was an important determinant of the location choices made by US investors Globerman and Shapiro, 2003).

In a country level analysis of the relationship between FDI and corruption, Cuervo-Cazurra (2006) found that in general corruption discourages inward investment. However, behavioural differences with respect to the home country of foreign investors were identified. That is, investment from countries that were signatories to the OECD convention on combatting bribery was deterred by corruption but investment from countries where bribery is prevalent was not deterred but maybe even encouraged. Hakkala et al (2008) analysed the relationship between FDI and corruption using firm level data on Swedish outward investment and found that Swedish firms were less likely to invest in countries where corruption was prevalent. In a cross country study of the relationship between FDI and institutional quality, including corruption, Bénassy-Quéré et al (2007) found good institutions to have a positive effect on FDI. Finally, in an African study of Ugandan firms, Fisman and Svensson (2007) found a robust and statistically significant negative relationship between corruption and firm growth. However, this study did not specifically address foreign firms or inward investment but it does lend support to the view that corruption tends to reduce the attractiveness of a particular location to international investors. However, there is some evidence that corruption has positive effects on FDI and a small number of authors have reported this. In a country level study, Egger and Winner (2005) found a positive and statistically significant relationship between FDI and corruption. Similarly, Pantzalis et al (2008) used a sample of US owned MNEs and found that corruption tends to increase the gains from foreign investment in locations where the quality of governance is poor.

A small number of studies follow the arguments proposed in this paper and consider the impact of foreign investment on corruption rather than the reverse. Rose-Ackerman (2002) provides a 
clear argument that affiliates of multinationals have an obligation to not engage in corruption in countries in which they do business. Kwok and Tadesse (2006) consider whether MNEs might themselves affect levels of corruption in host countries. In a cross-country study of the relationship between FDI and corruption they find that MNEs do tend to restrain corruption. Equally, Larraín and Tavares (2004), in a country level study find that FDI is associated with lower levels of corruption, that is, FDI as a share of GDP tends to result in lower levels of corruption. This supports the view that spillover effects of good governance can result from FDI firms and good practices can be learned by domestic firms in the host country.

Swamy et al (2001) analyse the relationship between gender and corruption in a multi-country study combined with a micro-level study of Georgia. They find women to be less prone to corruption and countries in which women hold power to be less corrupt. They include a dummy variable for foreign ownership in their micro-level probit analysis of corruption in Georgia and find no statistically significant effect. Chen et al (2008) conducted a multi-country analysis of the micro and macro level determinants of corruption, finding that macro-level variables and, in particular, the bargaining power of firms to be important. Their logit regression model includes a dummy variable for foreign ownership, which they find to be statistically insignificant. Reinikka and Svensson (2006) provide a valuable discussion of the measurement of corruption, concluding that enterprise surveys and public expenditure tracking surveys to be useful methods.

Hunt and Laszlo (2012), in a study of Uganda and Peru, find that the burden of bribery is not borne disproportionately by the poor. Okada and Samreth (2012) used country level data to analyse the effects of foreign aid on corruption, finding multi-lateral but not bi-lateral aid to be associated with higher levels of corruption. Liu et al (2016) in a study of China show that, with decentralisation of government, bribery can be important at the local rather than national level and can vary according to the control rights of local officials. An interesting study of traffic violations and corruption in Moscow by Mironov (2015) found that firms with corrupt CEOs performed better than other firms in terms of revenue growth. 
A further possibility is that foreign firms have a neutral effect on corruption. That is, they simply adapt to local conditions and if corruption is the norm, they follow suit if that is established practice, despite possible consequences from their home country. Puck et al (2013) find that foreign firms operating in emerging markets shape their strategies to address location specific risks and adapt accordingly, if necessary following custom and practice. Since their analysis includes measures of corruption it would be reasonable to suppose that this adaptation to local conditions also encompasses practices with respect to bribery. Roy and Goll (2014) examine the influence of national culture on control of corruption and find this to be linked to indigenous characteristics. This would also imply that foreign firms adapt to, rather than to shape, local culture. Svensson (2003) uses firm level data for Uganda to analyse the determinants of corruption, finding variation by industry according to the firm's ability to pay and available alternatives.

Thus, in summary, so far as it considers the effects of foreign firms on bribery, the literature offers two main competing views. Some authors find that foreign firms help reduce corruption but the implications of the work of others is that they simply adapt to local conditions. Clearly, any study of corruption at the firm level is limited as such practices are generally illegal and certainly unethical and so data are not easy to find and the number of empirical papers is not extensive. Fortunately, the World Bank Enterprise Surveys do include some information on the extent to which corruption is evident and therefore it is possible to discriminate between these two views in the literature. Therefore, the first testable hypothesis is that firms adapt to local corruption rather than changing it, notwithstanding legal and political pressures in their home country.

Hypothesis 1: foreign firms in emerging markets are equally likely to pay bribes as local firms.

It is also possible that corruption influences the type of foreign ownership of the firm. Early work on these issues, such as Gomes-Carreres (1989) and (1990), emphasised the influence of transactions costs on the choice of joint ventures over other forms of foreign ownership. Corruption in this respect would serve to increase transactions costs and create a disposition towards joint ventures. In particular, it may induce a preference for joint ventures over a controlling interest in a local 
affiliate. In a firm level study of Vietnam, Nguyen and Van Dijk (2012) found that ownership mattered and that corrupt practices tended to favour state owned enterprises over privately owned firms. Furthermore, in an analysis of inward investment in Turkey, Tekin-Koru (2006) found that countries with similar levels of corruption in their domestic market tended to focus on joint ventures while in contrast, investment from countries with dissimilar levels of corruption in their domestic market tended to focus on ownership of subsidiaries. Smarzynska and Wei (2001) used firm level data from transition economies and found that corruption tends to increase the preference of foreign investors to work with a local partner through a joint venture relative to acquiring a controlling interest in an affiliate. Javorcik and Wei (2009) used a probit model to analyse investment in transitional countries, focussing on both the decision to invest in a particular location and the choice of entry mode into a foreign market. They found that the presence of corruption increases the tendency for investment to take place through joint ventures. Chen and Hennart (2002) found Japanese firms investing in the US more likely to choose joint ventures in the presence of market barriers. In a study of foreign affiliates of Japanese firms, Makino and Neupert (2000) found institutional forces to be an important determinant of the selection of a joint venture over other forms of direct investment. From this literature, it is reasonable to propose that the relationship between the payment of bribes by foreign owned firms in any particular location depends on the degree of foreign ownership of the firm. That is, following Smarzynska and Wei (2001) and Javorcik and Wei (2009), we expect a difference in behaviour between joint ventures and foreign controlled firms with respect to corruption. This leads to the second testable hypothesis.

Hypothesis 2: the propensity to pay bribes is different between firms with low levels of foreign ownership (joint ventures) and those with higher (controlling) levels of foreign ownership.

Barbopoulos et al (2014) find that high levels of corruption in emerging markets had a positive effect on shareholder wealth for UK firms making resource seeking investments. They attribute these effects to a similar process to that described by a number of authors. That is, corruption may actually make a positive contribution by allowing firms to by-pass excessive bureaucracy where it exists. This is examined by Méon and Weill (2010), who showed that in a 
sample of developed and developing countries levels of efficiency increased following corrupt behaviour where the institutions were ineffective. Wang and You (2012) examined the effects of corruption on firm growth in China and find that firms exhibit high growth rates despite extensive corruption. They attributed this effect to the ability of corruption to circumvent awkward bureaucracy. Gaviria, (2002) also found corruption and bureaucratic obstacles to be positively and closely related in a study of private firms in Latin America. Méndez and Sepúlveda (2006) used country level data to examine the relationship between economic growth and corruption and found evidence of the existence of an optimal level of corruption. They also found that high levels of corruption reduced economic growth but more moderate levels actually appeared to enhance it. Yet again the explanation offered was that bribes allowed firms to avoid adverse government policies or practices, which were costly in terms of senior management time and the effort required to understand complex regulations. This leads to two related testable hypotheses.

Hypothesis 3: the payment of bribes by firms is positively related to the extent of bureaucratic obstacles.

In empirical studies of bribery the role of the state in the host country is a common theme. Two factors are notable. The first in the frequency of bribes related to the procurement of government contracts. Nwabuz (2005) discusses the bribery of public officials by multinational firms to secure state patronage and increase the likelihood of their acquiring government contracts. This is particularly the case for foreign firms as their lower cost of capital compared to domestic firms can increase their ability to pay bribes and this reduces the number of domestic bidders (Evernett and Hoekman, 2001). Further, in a study of the effectiveness of The Organization for Economic Cooperation and Development (OECD) Convention on Combating International Bribery of Foreign Public Officials in International Business Transactions, Hamra (2000) found that kickbacks are necessary to win government contracts "in many parts of the world (p.44). This leads to a fourth testable hypothesis.

Hypothesis 4: the payment of bribes by firms is positively related to the procurement of government contracts. 
The second factor that recurs frequently in the corruption literature is the effect of political instability in the host country. Corruption of various types is more likely to thrive where there is unstable government as well as the existence of poor quality institutions (Mauro, 1995). This leads to the final testable hypothesis.

Hypothesis 5: the payment of bribes by firms is positively related to political stability and other aspects of civil society in the host country.

Although this analysis focuses heavily on foreign ownership, bureaucratic obstacles, the pursuit of government contracts and political stability, other factors may also influence the propensity of firms to pay bribes. Thus, several variables are used to control for possible effects. These are: the age (Olney, 2014) and size of firm (Harstad and SvenssenJ, 2011), the extent to which the firm exports (Olney, 2014) and the market structure faced by the firm (Rose-Ackerman 1975).

\section{Data}

\subsection{Data Sources}

This study uses data from various World Bank Enterprise Surveys (WBES) ${ }^{1}$. Details of these surveys can be found at: http://www.enterprisesurveys.org. These surveys are not conducted annually but at irregular intervals, often on different years for different countries. For example, Argentina was surveyed in 2006 and 2010 but China in 2005 and 2012. This restricts the number of countries that can be combined into a single cross-section. Even for a single country the data cannot normally be used as a panel. When a survey of the same country is repeated in a later year only a very small proportion of firms are included in both surveys. For example, Turkey was surveyed in 2009 and 2013. The 2009 survey of Turkey covered 1152 enterprises and the 2013 survey 1344 enterprises. Of these only 138 firms (10\% of the 2013 sample) appeared in both years. Since the survey of any one country in any one year contains predominantly different firms to the survey of the same country in a

\footnotetext{
${ }^{1}$ These surveys have been used extensively (see, for example, Dethier et al (2011) and Xu (2011) for surveys and Clarke (2011) and Jensen et al (2010) and Olney (2014) for studies on corruption).
} 
different year it is only possible to develop a sample of true panel data at the cost of the great majority of observations.

Thus, the nature of the data restricts analysis to cross-section but this study analyses two different cross-sections. Sample 1 comprises 41 countries from all major world regions surveyed in the period 2009-2010. A full list of the countries included and the number of observations from each is presented in Appendix 1. Sample 2 covers the period 2013-2015 but excludes Latin American countries, for which there were (at the time of writing) no surveys after 2010. Since the two crosssections do not comprise the same firms they cannot be formally compared but they do allow a means to assess whether key conclusions are valid in more than one time period. This provides some sense of behavioural consistency over time.

Appendix 1 presents details of the country composition of sample 1 (26,505 observations) and of sample 2 (23,194 observations). Appendix 2 presents a summary by sector of selected characteristics of sample 1 and Appendix 3 presents similar details for sample 2. A key feature of both samples is the heterogeneity of firms. The size of firms included in both samples varies considerably from a single owner ( 0 employees) to almost 38,000 workers in sample 1 and to 17,000 in sample 2. Both appendices show important variations between sectors in foreign ownership, exporting and in perceptions of key constraints. With two samples as diverse as these it is necessary to take firm heterogeneity into account. It should be noted that our sample includes only the firms surveyed. This creates the possibility that there exists sample selection bias, for example from the exclusion of firms that ceased trading or from the exclusion of foreign investors who were deterred by corruption. The data used also included a number of country level variables, which were taken from the World Bank’s World Development Indicators.

\subsection{Bribery Variable}

The WBES data include two sets of variables dealing with corruption. There are a number of questions relating to perceptions of corruption and a number of other questions relating to whether an individual firm actually paid a bribe or not. In the literature much research, for example Swamy et al 
(2001), focused on the act of bribery rather than upon perceptions. This study follows the same tradition but we do use perceptions of corruption as an explanatory variable (testing the proposition that an act of bribery is more likely if a firm considers corruption commonplace).

The questions related to bribery from the standardised part of WBES questionnaires are outlined in Appendix 4. Our dependent (outcome) variable is the variable bribe, which takes the value of 1 when the firm responds with a positive value of informal payments with respect to customs, taxes, regulations and the like in the current year and 0 for no payment. The full text of the relevant question is given in Appendix 4 as are the other (unused) questions relating to payment of bribes.

Information on bribery is necessarily sensitive and is exposed to some risk of response bias. WBES data is obtained from confidential surveys conducted independently from national governments. For all questions in the surveys responding firms have two options to not respond to a particular question - a blank entry or a "don’t know” response. Appendix 4 shows that for all questions in our sample (sample 1 and sample 2 combined) about 38\% of responses were blank entries and about 1\% were “don’t knows”. The percentages for both blank entries and “don’t knows” are also given for a number of selected questions for comparison. For the question used there was an unusually low proportion of blank responses (1.2\%) but a much higher proportion of "don’t know" responses (about 10\%). For the questions relating to bribery responding firms were given an additional option of "refuse to answer". About 7\% of responding firms refused to answer. No measure of bribery is ever likely to be wholly free of mis-reporting. It is certainly possible that firms refusing to answer the question do so to avoid incrimination. Nonetheless, the use of the WBES survey and the selection of the particular question offers some reassurance that firms that did respond were not particularly likely to mis-report when alternative responses where available.

Appendix 5 presents details of response rates to the same question by country. Unsurprisingly, this reveals substantial differences between countries of firms reporting payment of bribes. It underlines the need to include variables to capture country differences, particularly with respect to governance. 


\subsection{Foreign Ownership Variables}

For foreign ownership we followed Lu et al (2010) and Kimura and Kiyota (2007) and used equity share as a measure of foreign ownership. Thus, foreign ownership is defined as the presence of any foreign equity in the enterprise. It is more difficult to define a joint venture. Hennart and Zeng (2005) provide the most commonly used definition, that is, a joint venture is a partnership between firms, and they discuss the essential features of such a partnership. Boersma et al (2003) emphasise the importance of relationship trust in joint ventures. Based on such arguments we consider two different types of $(0,1)$ measure based on equity share as a proxy for the degree of trust likely to be required. These were defined as:

- foreign1 - 1 for any foreign ownership, 0 otherwise

- foreign3 - 1 for $50 \%$ or more foreign ownership, 0 otherwise.

A separate question in the WBES data asks the firm whether or not it is a joint venture with a foreign partner. The $(0,1)$ variable jointvent takes the value of 1 for a positive response and 0 otherwise. For conciseness we use only the foreign 1 variable in the probit and IWPRA analyses. All three foreign ownership variables are used in the propensity score matching analysis.

\subsection{Firm level control variables}

Following the finding by Swamy et al (2001) that females are less likely to engage in corruption we defined two variables for female participation in the firm:

- femown $(0,1)$ takes on the value of 1 if some owners of the firm are female,

- $\quad$ emman $(0,1)$ takes on the value of 1 if the senior manager of the firm is female.

A number of authors, such as Svensson (2003), link the payment of bribes to the firm's ability to pay. Mironov (2015) found that firms with corrupt CEOs performed better. To capture the link between firm performance and bribery effects we included the following variables:

- $\quad \boldsymbol{s p w}$ - sales per worker (current US \$) 
- $\quad \boldsymbol{p p w}$ - profit per worker (current US \$)

- growth - the percentage growth in turnover relative to 3 years earlier, following the analysis linking growth and corruption by Fisman and Svensson (2007).

- export - the share of exports in total sales. This is a performance variable since an extensive literature suggests that only better performing firms export.

Other authors, for example Méon and Weill (2010), have linked the payment of bribes to overcoming obstacles faced by firms and the WBES questionnaire includes a number of questions related to this. Each are scored from 0 (no obstacle) to 4 (very severe obstacle). For conciseness we grouped a number of these into the following measures:

- infra reflects perceived infrastructure constraints. It is defined as the mean (0-4) score for the importance of obstacles arising from each of electricity, telecommunications and transport.

- burcy represents perceived constraints arising from day to day governance. It is defined as the mean score for each of customs, tax administration, business licensing and labour regulation.

- polity is derived from perceived constraints arising from civil society. This variable is the mean score of responses to each of crime, political instability, corruption and the courts.

The remaining firm level control variables comprised:

- size, the firm's size class from micro to large, reflecting the argument by Chen et al (2008) that bargaining power is important in understanding bribery.

- govtbid, $(0,1)$ takes the value of 1 if the firm had bid for a government contract over the most recent 3 years.

- local a $(0,1)$ variable, taking on the value of 1 where the firm's main market is local and national another $(0,1)$ variable where the firm's main market is national. These variables are based on the finding by Liu et al (2016) that bribery is often local.

- age, the age of the firm in years. This acts as a proxy for experience and learning by doing. 
- mgrexp, the number of years of experience of the firm's senior manager, also intended to capture learning by doing.

- degree, the proportion of workers with university degrees. A number of previous studies have suggested that highly educated workers are less likely to be corrupt.

\subsection{Country level variables}

The role of the country level variables is to capture the most important differences in behaviour specific to individual countries. The following variables were included;

- gdpcap - GDP per capita, following the finding by authors such as Mauro (1995) of the link between GDP per capita and corruption.

- regeff - regulatory efficiency (distance to frontier score 0-100). A number of authors, including Globerman and Shapiro (2002), have linked corruption to regulatory inefficiency.

- edsecon and edtertiary - enrolment ratios in secondary and tertiary education. Again capturing the effects of education on corruption.

- enterprise - new business registrations per 1000 persons. A number of authors such as Roy and Goll (2014) emphasise the role of local business culture in corruption.

- $\quad$ natresrents - natural resource rents as a percentage of GDP.

- tradeopen - openness to trade, measured by international trade as a percentage of GDP. Trade reduces market and, hence, bargaining power for domestic firms.

\section{Methodology}

\subsection{Probit fixed effects model}

The first part of the analysis uses a probit fixed effects model, common with previous studies of corruption (see, for example, Swamy et al, 2001). Details of the functional form and its limitations are in Baltagi (2008). The initial specification was a standard probit model such that:

$$
\operatorname{Pr}(\text { bribe }=1)=F\left(X^{\prime} \beta\right)
$$


where $\operatorname{Pr}($ bribe $=1)$ is the probability that the $(0,1)$ variable bribe takes on the value of 1 (the firm paid a bribe), $\mathrm{F}$ is the cumulative standard normal distribution, $\mathrm{X}$ is the vector of explanatory variables and $\beta$ the vector of coefficients to be estimated.

Although the sample is cross-section rather than panel it was considered it important to control for the possibility that one industry might be more prone to bribery than another or more affected by cumbersome bureaucracy. To capture these influences industry fixed effects was included in the model. The resulting model is expressed:

$$
\operatorname{Pr}(\text { bribe }=1)=F\left(X^{\prime} \beta+\gamma\right)
$$

where $\gamma$ is a vector of industry dummy variables.

The literature raises concerns about potential bias affecting average coefficients in the probit model when fixed effects are used (see Green, 2004 and Fernández-Val, 2009). These issues are generally considered to have much less consequence for marginal coefficients. Accordingly, marginal rather than average coefficients are reported.

\subsection{Instrumental Variables Probit Model}

As discussed in the review of literature an extensive body of work exists that sees the presence of corruption as a deterrent to inward foreign direct investment. A small but growing literature, of which this study is intended to contribute, considers the possibility that foreign ownership might itself change the incidence of corruption. This implies a dual causality - that corruption affects inward investment but inward investment also affects corruption. An important consequence of this is that the probit estimates may be biased and inconsistent. To address this, an instrumental variables version of the probit model (probit model with continuous endogenous regressors) was used. This model essentially adapts and extends the probit model to allow for one or more endogenous regressors.

The probit instrumental variables (probit IV) model retains the key features of a standard IV

model. Instruments are required to be (a) related to the relevant independent variable(s) (the instrument is informative) and (b) uncorrelated with the (unobserved) disturbance term (the instrument is valid). As with standard IV estimation it is necessary to test for weak instruments. For estimation the ivprobit command in stata14 was used with weakiv to test for weak instruments. The 
ivprobit routine allows for two different estimation techniques - a maximum likelihood and a twostep estimator. The latter approach was used as weakiv is only appropriate with the two-step estimatior. For a more detailed exposition of these techniques readers are referred to Wooldridge (2010).

For the estimation of the probit IV model two further variables were added. The model is only appropriate when the variable that is instrumented is continuous. To satisfy this condition the $(0,1)$ variable foreign1 was replaced with the continuous variable foreign (the share of the firm owned by private foreign entities). As an instrument for the endogenous variable foreign the variable licensing was used. This variable takes the value of 1 if the firm was using technology licensed from a foreign company (other than computer software) and 0 otherwise. The theory of FDI focuses on the exploitation of ownership advantages in the form of know-how in foreign locations. This provides a conceptual basis for an association between foreign ownership and payments for intellectual property (the informative property of the instrument). The firm-level decision to license foreign technology is part of the firm's supply decision making and unlikely to be related to either demand side firm level decisions (for example, which markets to sell to) or to country wide variables. In short, as an instrument the variable licensing is valid.

\subsection{Propensity score matching}

In common with any statistical model the probit specification has limitations. A particular area of concern in this study is that it does not allow sufficiently for heterogeneity of firms. That is, it imposes the same behavioural model on all firms irrespective of whether they are similar to each other or not. To provide a better examination of the hypotheses, matching techniques are used to ensure closer comparability between those firms that pay bribes with those that do not. As noted by Mallick et al (2013) propensity score matching reduces sample selection bias by creating a carefully matched control group. As they note this is particularly useful where selection bias arises from endogeneity, for example when both foreign ownership and bribes are co-determined. Borin and Mancini (2016) also advocate the use of propensity score matching to address sample selection bias, It is not possible 
to observe the same firm in two different scenarios (say with or without foreign ownership) but it is possible to create a counter-factual using a company with very similar characteristics in all respects other than foreign ownership. These properties make propensity score matching a particularly useful method for analysing our data.

The central feature of matching analysis is the relationship between a treatment variable and an outcome variable. In this study the treatment variable is foreign ownership (defined in three different ways) and the outcome variable indicates whether the firm pays a bribe or not. A simple approach would be to compare a sample of foreign owned firms with a sample of other firms and test whether there is a statistically significant difference in the payment of bribes between the two. Unfortunately such an approach would almost certainly produce biased results unless the treated and control groups closely resemble each other in all relevant attributes other than the treatment. The selection of a control group that satisfies these conditions is known as a matching approach. It seeks to replicate the process of experimental random sampling using non-experimental observed data. ${ }^{2}$

The standard matching approach considers three key parameters:

- ATE - the average treatment effect in the population (defined as all treated and untreated firms or individuals).

- $\quad$ ATT - the average treatment effect for treated firms (foreign owned firms in this paper)

- $\quad$ ATNT - the average treatment effect for untreated firms (firms that are not foreign owned).

These are defined as:

$$
\begin{aligned}
& \operatorname{ATE}=\mathrm{E}\left(\mathrm{Y}_{1 \mathrm{i}}-\mathrm{Y}_{0 \mathrm{i}}\right) \equiv \mathrm{E}\left(\beta_{\mathrm{i}}\right) \\
& \mathrm{ATT}=\mathrm{E}\left(\mathrm{Y}_{1 \mathrm{i}}-\mathrm{Y}_{0 \mathrm{i}} \mid \mathrm{D}_{\mathrm{i}}=1\right) \equiv \mathrm{E}\left(\beta_{\mathrm{i}} \mid \mathrm{D}_{\mathrm{i}}=1\right) \\
& \text { ATNT }=\mathrm{E}\left(\mathrm{Y}_{1 \mathrm{i}}-\mathrm{Y}_{0 \mathrm{i}} \mid \mathrm{D}_{\mathrm{i}}=0\right) \equiv \mathrm{E}\left(\beta_{\mathrm{i}} \mid \mathrm{D}_{\mathrm{i}}=0\right)
\end{aligned}
$$

\footnotetext{
${ }^{2}$ For a more detailed exposition of matching techniques see Dehejia and Wahba (2002) and Deheja (2005) and for applications see Sianesi (2004) and Blundell et al (2005).
} 
where $\mathrm{Y}$ is the outcome (payment of a bribe), with subscript 1 for those firms that are treated and subscript 0 for those that are not. $\mathrm{D}$ is an indicator of the treatment received (by definition 1 for treated (foreign owned) and 0 for untreated).

As discussed above the simplest estimator of the effects of treatment (foreign ownership) on the outcome (payment of a bribe) is simply to compare the means of the treated (foreign owned) firms with the untreated (domestic). However, such an approach is biased, which results from two possible sources: bias from selection on observables (comparing firms that are not comparable or weighting comparable individuals differently) and bias from selection on unobservable variables. The latter is a version of the problem of possible excluded confounding variables or omitted variable bias. It is never certain that an important confounding variable has not been excluded but it is important to demonstrate that steps have been taken to reduce this risk. In this study the most common approach is used, that is to include potentially relevant variables for which observable data are used. For example, here selected variables include firm size, a measure of bureaucratic obstacles, industry dummies and others.

Reducing bias from selection on observables requires a more complex explanation. To estimate ATT it is necessary to assume that all relevant differences are captured in the observed attributes of the treated and untreated firms. That is, that no bias from selection on unobservables is present and that both treated and untreated firms are observed to have shared attributes. Selection is performed using a propensity score $\mathrm{p}(\mathrm{x})$ where:

$$
\mathrm{p}(\mathrm{x}) \equiv \mathrm{P}(\mathrm{D}=1 \mid \mathrm{X}=\mathrm{x})=\mathrm{E}(\mathrm{D} \mid \mathrm{X}=\mathrm{x})
$$

The most common approach uses a probit model to define the propensity score and this is followed here. Unlike the model discussed earlier this probit model is not intended to be itself a causal model. It acts as a way of identifying and summarising the key characteristics of the treated (foreign owned) firms. The next step is to match each treated (foreign owned) firm with a comparable untreated (domestic) firm. There are many different ways in which this matching can be done. The most common is to select comparison firms according to the nearest neighbour principle. 
For each foreign firm this involves selecting an untreated (domestic) firm with the closest value of the propensity score. The matching procedure used here was nearest neighbour sampling with replacement. Other methods of matching, including several using kernel densities, were also used. Kernel density matching with bootstrapped standard errors was used for this study.

The final step in the matching process is to assess how effective the process of matching was in selecting a control group from the untreated (domestic) firms that was comparable to the treated (foreign owned) group. In effect this is a check on the adequacy of the process of selecting observables and are not formal statistical tests but checks using descriptive statistics. These checks are reported in appendix 5 for sample 1 and appendix 6 for sample 2 .

There are two key assumptions of the matching estimator that require further consideration. The first is that there is no bias on unobservables. As with omitted variable bias in the regression model there is no certain method to eliminate the risk that an unobservable variable has resulted in bias. We have sought to reduce this risk by including as many variables as possible as observables. In developing propensity scores we used not only the control variables listed earlier but dummy variables for each sector. The second important assumption is that the treatment variable, foreign ownership, is exogenous. To address potential endogeneity of the treatment variable this study used a further estimator.

\subsection{Inverse Probability Weighted Regression Adjustment (IPWRA)}

As noted previously propensity score matching estimators help reduce sample selection bias arising from endogeneity. Inverse Probability Weighted Regression Adjustment (IPWRA) takes this one step further by explicitly modelling treatment effects as endogenous variables. The IPWRA technique is set out in detail in Cattaneo (2010) and Cattaneo et al (2013). IPWRA can also be seen as an extension of the matching approach to include interactions with another treatment variable. For example, it allows estimation of treatment effects of, say, foreign ownership and bureaucracy and the interaction between the two variables. 
To take into account that bureaucracy and foreign ownership simultaneously influence firm behaviour, we estimate treatment effects in the multi-treatment context. A matching approach with multiple treatments was first introduced by Lechner (2001). We have $\mathrm{M}+1$ treatments, the $\mathrm{M}$ original treatments plus a joint effect of the $\mathrm{M}$ treatments combined. The model is also estimated with no treatment effects - see Czarnitzki et al.,(2007) and Radicic and Pugh (2016). The average treatment effect on the treated (ATT) effect is then calculated as:

$$
A T T=E\left(Y^{m} \mid T=m\right)-\left(Y^{l} \mid T=m\right)
$$

where $m$ denotes the treatment level, $l$ represents the comparison group (the treatment level to which $m$ is compared) and $Y^{m}$ and $Y^{l}$ denote outcomes in states $m$ and $l$ respectively.

The main attraction of the IPWRA estimator is its property of double robustness. Double robustness implies that either the treatment model or the outcome model (or both) have to be correctly specified for the estimator to produce consistent treatment effects (Hirano et al. 2003). That is, provided either the model of the treatment or the model of the outcome is correctly specified the model will result in estimates of treatment effects with a lower bias than other estimators. The Monte Carlo analysis of Busso et al. (2014) supports the use of the IPWRA estimator.

The IPWRA estimator consists of three steps. The first of these is to estimate the propensity score for the treatment model. This, for example, provides estimates of the probability that a firm is foreign owned. Propensity scores are estimated by a multinomial logit model, incorporating all four treatment levels: neither bureaucratic constraints nor foreign ownership; only bureaucratic constraints; only foreign ownership; and both. The propensity scores enable firms to be matched within each treatment level. The second step is to estimate a series of regressions in which the inverse of the estimated propensity scores are used as weights on covariates $X$ and our treatment dummies. The final step is to compute the ATT effect, that is, the difference in the weighted averages of the predicted outcomes (for technical details see Wooldridge 2010). This three-step approach provides consistent estimates given the underlying assumption of the independence of the treatment from the predicted outcomes once covariates are modelled in steps 1 and 2. The standard errors reported are of the Huber/White/sandwich type that take into account that the estimates are computed in a three-step approach (Emsley et al. 2008). 


\section{Estimation and Results}

\subsection{Probit Analysis}

The results of the probit analysis are in Table 1, where the coefficients are the marginal effects $(\mathrm{dF} / \mathrm{dx})$ rather than averages because country dummy variables were used in estimation. Coefficients for country dummies are not reported. Note also that the software used (STATA 14) automatically deletes observations for which there are missing observations. This creates a difference in the number of observations between the general and specific version of models as removing variables reduces missing observations. Results are reported for sample 1 (2009-10) and for sample 2 (2013-2015), in each case for a general (all variables included) and a specific (control variables that were jointly statistically insignificant excluded) version of the model. Results are reported only for the foreign1 (any foreign ownership) variable.

\section{Table 1}

For both sample 1 and sample 2 the coefficient for foreign ownership is statistically insignificant at $90 \%$ confidence levels or higher. Hypothesis 1 (that foreign ownership has no effect on the propensity to pay bribes) cannot be rejected. In both sample 1 and sample 2 the coefficient for perceived (by the firm) bureaucratic obstacles is positive and statistically significant at 99\% confidence. In consequence, hypothesis 3 (that bribery is related to bureaucratic constraints) also cannot be rejected. With respect to the relationship between bribery and perceived constraints from civil society - polity (encompassing political instability, perceived corruption, crime and the courts) the results differ between sample 1 and sample 2 . Whether or not the firm had sought government contracts was a statistically significant determinant of bribery in both samples (at $99 \%$ for sample 1 but only at $90 \%$ for sample 2). These findings are such that hypothesis 4 (that bribery is positively related to government contracts) cannot be rejected. For sample 1 the coefficient for polity is statistically insignificant at $90 \%$ or higher confidence levels. For sample 2 it is statistically significant at $99 \%$ and positive. Hypothesis 5 (that constraints related to polity are positively associated with bribery) cannot be rejected for sample 2 but is rejected for sample 1 . 
With respect to other control variables, GDP per capita was found to have a statistically significant and negative effect on bribes at $99 \%$ confidence in both samples. This finding is consistent with the view that bribery is less prevalent in higher per capita income countries. A number of other control variables were significant in one sample but not the other. For example, infrastructure obstacles and trade openness were found to have positive and statistically significant effects on bribes in one sample but not the other.

\subsection{Probit with a Continuous Endogenous Regressor (Instrumental Variables)}

The results of the instrumental variables (IV) version of the probit model are in Table 2. Note that the IV version of the probit model requires the endogenous regressor to be continuous. For this analysis the variable foreign (the percentage foreign ownership of the firm) replaced the $(0,1)$ variable foreign1. The variable licensing (whether or not the firm uses foreign technology under licence) was used as an instrument for foreign. Tests for weak instruments suggest that the hypothesis that licensing is a weak instrument for foreign can also be rejected for any reasonable level of confidence.

Table 2

Table 2 reports only the "specific" version of the IV probit model. The model was initially run with the full set of variables listed in Table 1 but the specifications reported are those with (jointly) statistically insignificant variables omitted. With respect to the foreign ownership variable the findings are consistent with the earlier probit model. For both sample 1 and sample 2, foreign ownership was found to have no statistically significant effect on whether or not firms paid a bribe.

With respect to other potential determinants of bribery the main findings of the IV probit model were:

- larger firms (variable size) were statistically significantly less likely to report having paid a bribe in both sample 1 and sample 2

- perceived bureaucratic obstacles (burcy) were statistically significantly more likely to result in a reported bribe in both samples. 
- perceived obstacles arising from the political and legal environment (polity) were also statistically significantly more likely to result in reported bribery in sample 1 and in sample 2 .

- of the country level variables per capita GDP and secondary school enrolment ratios were found to be statistically significantly associated with a lower propensity to bribe in both samples.

- natural resource rents (as a share of GDP) and (perversely) tertiary education enrolment ratios were found to have statistically significant effects of increasing reported bribery.

\subsection{Matching Analysis}

To construct the propensity score we used probit models for each of the three $(0,1)$ foreign ownership variables, that is, foreign1 (any foreign ownership), foreign3 (majority foreign ownership) and jointvent (joint venture). In the first instance all control variables (see section 3) were used to estimate the probit model and sector dummies were also included. The final propensity score was created after removing those variables that were jointly insignificant from the probit models. Note that these estimates were not intended as a behavioural model of foreign ownership in the way that the probit model in the preceding section examined the determinants of bribery. The purpose of the probit analysis in this case was to identify the key characteristics of foreign owned firms so that a closely matched control group could be selected to provide a propensity score. ${ }^{3}$ These were then used to create matched control groups using the psmatch2 application in STATA statistical software (see Leuven and Sianesi (2012) for details).

There are several different ways of matching using a propensity score. The analysis presented here used kernel density matching with bootstrapped standard errors. Table 3 reports the results for sample 1 (2009-10). Tests were conducted for each variable relating to our five hypotheses. Checks for bias on observables are reported in Appendix 6. The results show that neither any foreign ownership (foreign1) nor majority foreign ownership (foreign3) had any statistically significant effect on the payment of bribes by firms in sample $1(2009-10)$. The $(0,1)$ variable for joint ventures did

\footnotetext{
${ }^{3}$ The results of these probit regressions are not reported but are available from the authors.
} 
reveal a positive and statistically significant effect on the payment of bribes but only at $90 \%$ confidence. In consequence, hypothesis 1 (foreign ownership does not affect bribery) cannot be rejected for foreign ownership in general. Hypothesis 2 is also not rejected, as the (marginally) statistically significant positive effect for joint ventures reveals a behavioural difference from other forms of foreign ownership.

\section{Table 3}

The bureaucracy variable was re-defined as a 0,1 variable taking on the value of 1 if the firm reported a mean score of 2 (moderate difficulty) or higher. The results showed perceived bureaucratic obstacles to have a positive and statistically significant effect (at 99\%) on bribery. Hypothesis 3 was accordingly not rejected. Likewise whether or not the firm had bid for a government contract was positive and statistically significant at $99 \%$ confidence, such that hypothesis 4 (that bids for government work are positively associated with bribery) was also not rejected. Finally the variable polity (capturing perceptions of political instability, crime, corruption and the courts) was found to have a statistically significant effect on bribery.

Table 4 presents comparable results of the matching analysis for sample 2 (2013-15). Checks for bias on observables are in Appendix 7. With respect to foreign ownership there is one conclusion that differs from the findings for the earlier sample. The effect of joint ventures on bribery (significant only at $90 \%$ confidence in sample 1) is not statistically significant. For the later sample no form of foreign ownership has a statistically significant effect (at $90 \%$ confidence or higher) on bribery; foreign1, foreign3 and jointvent are all statistically insignificant. This means that neither hypothesis 1 (foreign firms do not differ from others with respect to bribery) nor hypothesis 2 (the form of foreign ownership does not affect the propensity to bribe) can be rejected. As with the earlier sample perceived bureaucratic obstacles have a statistically significant effect (at 99\%) on the payment of bribes, such that hypothesis 3 (a positive relationship between bureaucracy and briber) also cannot be rejected. As with sample 1 there are statistically significant and positive effects for (a) bidding for government contracts (at 95\%) and for (b) polity (perceived constraints from political instability, 
crime, corruption and the courts), at 99\% confidence. In consequence, neither hypothesis 4 (that bribery is positively related to government procurement) nor hypothesis 5 (that bribery is positively related to perceptions of obstacles arising from civil society) can be rejected.

Table 4

The key features of the propensity score matching analysis are that all types of foreign ownership (any, majority or joint venture) have no statistically significant effects on bribery when sample selection bias is controlled by a matching procedure. The only exception was that joint ventures were found to be marginally significant (at 90\%) in sample 1. Bureaucracy, bidding for government contracts and perceived obstacles caused by political instability, corruption, crime and the courts (polity) were all found to have a statistically significant effect of increasing bribery in both sample 1 and sample 2 .

\subsection{Inverse Probability Weighted Regression Adjustment (IPWRA) Analysis}

The IPWRA represents a number of important extensions to the matching model. It makes treatment effects endogenous to the model, allows interactions between two different treatment effects and, most importantly, it has the property of double robustness. In this section the analysis focuses on the effects of foreign ownership on bribery jointly with a series of partner treatments: bureaucracy (burcy), perceived obstacles arising from political instability, crime, corruption and the courts (polity) and bidding for government contracts (govtbid).

Table 5 presents the results of the IPWRA analysis for sample 1 . The table is divided into three sections Reading across the first row of the first section gives the estimated treatment effects (ATT) for foreign1, bureaucracy and both treatments jointly compared to the counter-factual of no treatment. Foreign ownership (foreign1) has no statistically significant effect but bureaucracy has a positive and statistically significant effect (at 99\%) on the payment of bribes. The combined effect of both foreign ownership and bureaucracy is also positive and statistically significant but the table shows that this finding is dominated by the effect of perceived bureaucratic obstacles. Reading down the first column in the first section provides estimates of the ATT derived from removing rather than 
adding a treatment effect (the double robustness property). The removal of foreign1 as a treatment is shown to have no statistically significant effect but the removal of perceived bureaucracy has a statistically significant (99\%) negative effect on bribery, that is, removing burcy as a treatment reduces bribery. The combined effect of removing both foreign ownership and bureaucracy is also negative and statistically significant at $99 \%$ confidence. Again this finding is dominated by the effect of bureaucracy.

Table 5

The second section of Table 5 presents the IPWRA estimates using foreign ownership and polity (perceived constraints from political instability, crime, corruption and the courts) as treatments. Reading across the first row gives treatment effects compared to the counter factual of no treatment. Foreign ownership is found to have a positive and statistically significant effect on bribery but only at 90\% confidence. Both Polity and the combined effect of two treatments were found to have positive and statistically significant (at 99\%) effects on bribery. Reading down the first column of the second section gives the effects of removing rather than adding each treatment. The removal of foreign ownership has no statistically significant effect. This means that the conclusion that it had a (marginally) significant effect when added is not robust. The removal of polity as a treatment was also statistically insignificant, suggesting a lack of robustness with the earlier finding of a statistically significant effect. The third section considers foreign ownership and bidding for government contracts as treatment variables. Reading across the first row shows a not statistically significant treatment effect for foreign ownership but a positive and statistically significant (99\%) effect of government contract bids on bribery. Reading down the first column of the third section shows that these findings are robust. The removal of foreign ownership as a treatment has no statistically significant effect but the removal of government bids as a treatment has a statistically significant (99\%) negative effect on bribery.

The final section of Table 5 presents the IPWRA analysis using foreign ownership and profitability per worker (ppw) as treatments. The inclusion of a profitability indicator seeks to reflect 
the argument that more efficient, more competitive firms have less need to resort to bribery. The results again suggest that neither foreign ownership nor profit per worker had statistically significant effects on bribery in sample 1.

Table 6 presents the IPWRA analysis for sample 2 (2013-2015). As with the analysis for sample 1 the first section considers the effects on bribery of foreign ownership (foreign1) and perceived bureaucracy (burcy) as treatments. Reading across the first row of the first section shows no statistically significant effect of foreign ownership but a statistically significant (at 99\%) of bureaucracy. Jointly the two treatment variables are also statistically significant. Reading down the first column of the first section gives the effects of removing rather than adding treatment effects. The removal of foreign ownership has no statistically significant effect but the removal of bureaucracy has a negative and statistically significant effect (at 99\%) on bribery. The second section considers foreign ownership and polity as treatment effects. Reading across the first row of this section shows, again, no statistically significant effect of foreign ownership on bribery but a statistically significant effect (at 99\%) of polity on bribery. The first column of the section shows the removal of foreign ownership as a treatment to have no statistically significant effect but the removal of polity to have a statistically significant (99\%) negative effect on bribery. The final section considers foreign ownership and bidding for government contracts as treatment variables. Adding foreign ownership (first row of the section) or removing it (first column) as a treatment has no statistically significant effect. Including bids for government contracts as a treatment variable (first row) has a statistically significant positive effect on bribery and removing it (first column) a statistically significant negative effect, both at 95\% confidence.

The IPWRA analysis for sample 2 differs from that for sample 1 in one important respect. More profitable firms (as measured by $\mathbf{p p w}$ ) were found to have a statistically significant negative effect on the payment of bribes, making more profitable firms less likely to pay bribes than less profitable ones. Since different samples cannot be directly compared with each other it is hard to be certain why the findings of sample 1 differ from those for sample 2 other than to note that this is a possibility for further research. 


\section{Table 6}

The main points that emerge from the IPWRA analysis of both sample 1 and sample 2 are that foreign ownership has no significant effect on bribery. These findings are robust with one exception. The effect of bribery, when combined with the civil society variable polity is not fully robust in sample 1. Bureaucracy, polity and bidding for government contracts are all found to have statistically significant effects associated with a greater propensity to engage in bribery. Again these findings are robust in both sample 1 and sample 2 with one exception, the findings for polity in sample 1 are not robust. In sample 2 but not in sample 1, profitability is also found to have a statistically significant effect in reducing bribery.

\section{Conclusions}

\subsection{Methodological Limitations}

Most estimators are subject to limitations and it is worth drawing attention to those affecting the techniques used in this study. In the instrumental variables probit model the study found licensing (of foreign technology) to be a weakly exogenous instrument for foreign ownership but the possibility remains that it is not strongly exogenous. There are risks of endogeneity arising from issues related to confounding variables - omitted variables bias with probit, bias on unobservables with propensity score matching and violation of the ignorability assumption with IPWRA. There are also risks of endogeneity if both foreign ownership and bribery share some common determinants. To address these issues the on-line appendix reports robustness checks using a bivariate probit model. This finds that both bribery and foreign ownership do indeed share some determinants in common but that foreign ownership still does not have a statistically significant effect on whether firms pay bribes or not, when it is treated as an endogenous variable.

\subsection{Research Implications}

To date the literature on the effects of foreign firms on corruption in host economies is inconclusive. Existing studies are divided between those that argue that MNEs can bring about a reduction in 
bribery and those that argue the firms operating in international markets adapt to local conditions and practices. This study provides strong support for adaptation to local standards. It finds no difference in behaviour between foreign owned and domestic firms with respect to bribery in a sample of 41 emerging economies. This has important implications for countries with high levels of corruption where the institutions are weak.

The data used for the study are taken from surveys of existing firms, thus it was never the intention to address whether or not investment has been deterred by corruption. However, associated with the literature is an argument that corruption leads firms to prefer joint ventures over independent subsidiaries. This choice is more readily modelled by evidence on existing firms since it is possible to observe the choices that have been made with respect to ownership structure. No difference in the propensity to pay bribes with respect to the degree of foreign ownership, or whether or not the firm is a joint venture, was found in this sample.

This paper did not just address the literature from the perspective of foreign investment but also that concerning the wider determinants of corruption. In particular it focused on the role of three variables: bidding for government contracts and perceived obstacles arising from (a) bureaucracy and (b) civil society (political instability, corruption, crime and the courts). It finds robust evidence that all three variables are associated with a greater propensity for firms to pay bribes. Although not a focus of this study a wider range of "controls” were also used.

From a methodological perspective few previous studies were found in the area of international business or development that use matching techniques. The results of this study demonstrate the potential value of these techniques for future studies of the behaviour of MNEs with activities in developing regions. As far as can be ascertained no previous firm level study of corruption has used an IPWRA approach. In particular, studies which implicitly or explicitly compare the behaviour of foreign firms with unmatched domestic ones (without first creating a carefully matched control group) are at risk of making incorrect inferences. In this study there are a number of 
examples where spurious conclusions could have been reached if care had not been taken to ensure that like was compared to like.

\subsection{Implications for Policy}

The results have implications for managers of MNEs in developing countries. Along with a number of other studies, it is shown that MNEs must expect to adapt to local culture with respect to corruption in emerging markets. To date the evidence suggests that this need to adapt has tended to override pressure from home country legislation to avoid corrupt behaviour. Practical as opposed to moral considerations have tended to dominate behaviour as opposed to rhetoric. An important reason for this is that bribery tends to be more prevalent where there are significant bureaucratic obstacles and excessive resources are required to circumvent them, that is, where host country institutions are weak. Firms should therefore expect behavioural norms to favour bribery where cumbersome and time consuming bureaucracy exists. As with other studies, no attempt has been made to suggest that bribery is a first best solution from the perspective of host economies. It clearly is not and huge welfare losses can result as well as providing a barrier to growth. However, the evidence is consistent with a view that bribery may, in some instances, be more efficient than a very burdensome bureaucracy. This suggests that policy measures designed to reduce corruption are only likely to be effective if accompanied by measures to streamline government procedures and practices affecting business operations. 


\section{REFERENCES}

1.Aidt T (2009), Corruption, institutions, and economic development, Oxford Review of Economic Policy, 25:2, 271-91

2.Baltagi B (2008). Econometric analysis of panel data. John Wiley \& Sons, Chichester.

3.Barbopoulos L, Marshall A, MacInnes C, and McColgan P (2014). Foreign direct investment in emerging markets and acquirers' value gains. International Business Review, 23:3, 604-619 4.Bénassy-Quéré A, Coupet $M$ and Mayer T (2007). Institutional determinants of foreign direct investment. The World Economy, 30:5, 764-782.

5.Boersma M, Buckley P and Ghauri P (2003). Trust in international joint venture relationships. Journal of Business Research, 56:12, 1031-1042.

6.Borin, A and Mancini M (2016). Foreign direct investment and firm performance: an empirical analysis of Italian firms. Review of World Economics, forthcoming

7. Busso M, DiNardo J and McCrary J (2014). New evidence on the finite sample properties of propensity score reweighting and matching estimators. Review of Economics and Statistics, 96:5, 885897

8. Cattaneo M (2010). Efficient semiparametric estimation of multi-valued treatment effects under ignorability. Journal of Econometrics, 155:2, 138-154.

9. Cattaneo M, Drukker D and Holland A (2013). Estimation of multivalued treatment effects under conditional independence. Stata Journal, 13:3, 407-450.

10.Chen S and Hennart J (2002). Japanese investors' choice of joint ventures versus wholly-owned subsidiaries in the US: The role of market barriers and firm capabilities. Journal of International Business Studies, 33:1, 1-18.

11. Chen Y, Yaşar M and Rejesus R (2008). Factors influencing the incidence of bribery payouts by firms: A cross-country analysis. Journal of Business Ethics, 77:2, 231-244.

12.Clarke G (2011). How Petty is Petty Corruption? Evidence from Firm Surveys in Africa. World Development, 39:7, 1122-32.

13.Cuervo-Cazurra A (2006). Who cares about corruption?. Journal of International Business Studies, 37:6, 807-822. 
14. Czarnitzki D, Ebersberger B and Fier A (2007). The Relationship between R\&D Collaboration, Subsidies and R\&D Performance: Empirical Evidence from Finland and Germany. Journal of Applied Econometrics, 22:7, 1347-366.

15.Dethier J-J, Hirn M and Straub S (2011). Explaining enterprise performance in developing countries with business climate survey data. The World Bank Research Observer 26.2, 258-309.

16.Egger $\mathrm{P}$ and Winner $\mathrm{H}$ (2005). Evidence on corruption as an incentive for foreign direct investment. European Journal of Political Economy, 21:4, 932-952.

17. Emsle, R, Lunt M, Pickles A and Dunn G (2008). Implementing double-robust estimators of causal effects. Stata Journal, 8:3, 334-353.

18.Evenett S and Hoekman B (2005) Government procurement: market access, transparency, and multilateral trade rules, European Journal of Political Economy, 21, 163-83

19.Fernández-Val I (2009). Fixed effects estimation of structural parameters and marginal effects in panel probit models. Journal of Econometrics, 150:1, 71-85.

20.Fisman R and Svensson J (2007). Are corruption and taxation really harmful to growth? Firm level evidence. Journal of Development Economics, 83:1, 63-75.

21.Gaviria A (2002). Assessing the effects of corruption and crime on firm performance: evidence from Latin America. Emerging Markets Review, 3:3, 245-268.

22. Hunt J and Laszlo S (2012). Is bribery really regressive? Bribery's costs, benefits, and mechanisms. World Development, 40:2, 355-372.

23. Liu Y, An Y and Zhang J (2016). Bribe payments under regulatory decentralization: Evidence from rights offering regulations in China. Journal of Banking \& Finance, 63, 61-75.

24.Globerman S and Shapiro D (2002). Global foreign direct investment flows: The role of governance infrastructure. World development, 30:11, 1899-1919.

25.Globerman S and Shapiro D (2003). Governance infrastructure and US foreign direct investment. Journal of International Business Studies, 34:1, 19-39.

26.Greene W (2004). The behaviour of the maximum likelihood estimator of limited dependent variable models in the presence of fixed effects. The Econometrics Journal, 7:1, 98-119. 
27.Habib M and Zurawicki L (2001). Country-level investments and the effect of corruption—some empirical evidence. International Business Review, 10:6, 687-700.

28.Habib M and Zurawicki L (2002). Corruption and foreign direct investment. Journal of International Business Studies, 291-307.

29.Hakkala K, Norbäck P and Svaleryd H (2008). Asymmetric effects of corruption on FDI: evidence from Swedish multinational firms. The Review of Economics and Statistics, 90:4, 627-642.

30.Hamra W, (2000), Bribery in International Business Transactions and the OECD Convention: Benefits and Limitations, Business Economics, 35:4, 33-46

31.Harstad D and Svenssen J, (2011) Bribes, Lobbying, and Development, American Political Science Review, February, 1-18

32.Hennart J and Zeng M (2005). Structural determinants of joint venture performance. European Management Review, 2:2, 105-115.

33. Hirano K, Imbens G and Ridder G (2003). Efficient estimation of average treatment effects using the estimated propensity score. Econometrica, 71:4, 1161-1189.

34.Holtbrügge D, Berg N and Puck J F (2007). To bribe or to convince? Political stakeholders and political activities in German multinational corporations. International Business Review, 16:1, 47-67. 35.Javorcik B and Wei S (2009). Corruption and cross-border investment in emerging markets: firmlevel evidence. Journal of International Money and Finance, 28:4, 605-624.

36.Jensen N, Quan L and Rahman A (2010). Understanding corruption and firm responses in crossnational firm-level surveys. Journal of International Business Studies 41.9, 1481-1504.

37.Kimura F and Kiyota K (2007). Foreign-owned versus Domestically-owned Firms: Economic Performance in Japan. Review of Development Economics, 11:1, 31-48.

38.Kwok C and Tadesse S (2006). The MNC as an agent of change for host-country institutions: FDI and corruption. Journal of International Business Studies, 37:6, 767-785.

39.Larraín B and Tavares J (2004). Does foreign direct investment decrease corruption?. Cuadernos de Economía, 41:123, 199-215. 
40. Lechner M (2001). Identification and estimation of causal effects of multiplie treatments under the conditional independence assumption, in: M Lechner and F Pfeiffer (eds.), Econometric evaluation of active labor market policies, Heidelberg, 43-58.

41.Leuven E and Sianesi B (2012). PSMATCH2: Stata module to perform full Mahalanobis and propensity score matching, common support graphing, and covariate imbalance testing. Statistical Software Components.

42.Lu J, Lu, Y and Tao Z (2010). Exporting behavior of foreign affiliates: Theory and evidence. Journal of International Economics, 81:2, 197-205.

43. Mallick S and Yang Y (2013). Productivity performance of export market entry and exit: Evidence from Indian firms. Review of International Economics, 21:4, 809-824.

44.Makino S and Neupert K (2000). National culture, transaction costs, and the choice between joint venture and wholly owned subsidiary. Journal of International Business Studies, 31:4, 705-713.

45.Mauro P (1995). Corruption and growth. The Quarterly Journal of Economics, 110:3, 681-712.

46.Méndez F and Sepúlveda F (2006). Corruption, growth and political regimes: cross country evidence. European Journal of Political Economy, 22:1, 82-98.

47.Méon P-G and Weill L (2010), Is Corruption an Efficient Grease? World Development, 38:3, 244259

48. Mironov M (2015). Should one hire a corrupt CEO in a corrupt country?. Journal of Financial Economics, 117:1, 29-42.

49.Nguyen T and Van Dijk M (2012). Corruption, growth, and governance: Private vs. state-owned firms in Vietnam. Journal of Banking \& Finance, 36:11, 2935-2948.

50. Nwabuzor A (2005), Corruption and development: new initiatives in economic openness and strengthened rule of law, Journal of Business Ethics, 59, 121-138

51. Okada K and Samreth S (2012). The effect of foreign aid on corruption: A quantile regression approach. Economics Letters, 115:2, 240-243.

52.Olney W (2014), Impact of Corruption on Firm-Level Export Decisions, Department of Economics Working paper, Williams College, Williamstown, MA 01267, USA 
53.Pantzalis C, Park J and Sutton N (2008). Corruption and valuation of multinational corporations. Journal of Empirical Finance, 15:3, 387-417.

54.Puck J, Rogers H and Mohr A (2013). Flying under the radar: Foreign firm visibility and the efficacy of political strategies in emerging economies. International Business Review, 22:6, 1021-33. 55. Radicic D and Pugh G (2016). R\&D programmes, policy mix, and the "European Paradox": evidence from European SMEs. Science and Public Policy, forthcoming

56. Reinikka R and Svensson J (2006). Using micro-surveys to measure and explain corruption. World Development, 34:2, 359-370.

57.Rose-Ackerman S (2002). "Grand" corruption and the ethics of global business. Journal of Banking \& Finance, 26:9, 1889-1918.

58.Roy A and Goll I (2014). Predictors of various facets of sustainability of nations: The role of cultural and economic factors. International Business Review, 23:5, 849-861

59.Shleifer A and Vishny R (1993). Corruption. The Quarterly Journal of Economics, 108:3, 599-617

60.Smarzynska B and Wei S (2001). Pollution havens and foreign direct investment: dirty secret or popular myth? (No. w8465). National Bureau of Economic Research, Cambridge, Mass.

61. Svensson, J. (2003). Who Must Pay Bribes And How Much? Evidence From A Cross Section Of Firms. Quarterly Journal of Economics, 118, 1. 207-230

62. Swamy A, Knack S, Lee Y and Azfar O (2001). Gender and corruption. Journal of Development Economics, 64:1, 25-55.

63.Tekin-Koru A (2006). Corruption and the ownership composition of the multinational firm at the time of entry: Evidence from Turkey. Journal of Economics and Finance, 30:2, 251-269.

64.Truex R (2011), Corruption, Attitudes, and Education: Survey Evidence from Nepal, World Development, 39:7, 1133-1142

65.Wang Y and You J (2012). Corruption and firm growth: Evidence from China. China Economic Review, 23:2, 415-433.

66.Wei S (2000). How taxing is corruption on international investors?. Review of Economics and Statistics, 82:1, 1-11. 
67. Wooldridge J (2010). Econometric Analysis of Cross Section and Panel Data. (2 ${ }^{\text {nd }}$ edition). MIT Press, Cambridge, Mass.

68.Xu L (2011). The effects of business environments on development: Surveying new firm-level evidence. The World Bank Research Observer 26.2, 310-340. 
Table 1: Probit estimates, dependent variable $=$ bribe $(0,1)$

\begin{tabular}{|c|c|c|c|c|c|}
\hline \multirow[t]{3}{*}{ Variable } & \multirow[t]{3}{*}{ Label } & \multicolumn{2}{|l|}{ Sample 1 (2009-10) } & \multicolumn{2}{|l|}{ Sample 2 (2013-2015) } \\
\hline & & General & Specific & General & Specific \\
\hline & & $\mathrm{dF} / \mathrm{dx}$ & $d F / d x$ & $\mathrm{dF} / \mathrm{dx}$ & $\mathrm{dF} / \mathrm{dx}$ \\
\hline \multicolumn{6}{|l|}{ Firm level variables: } \\
\hline \multirow[t]{2}{*}{ foreign ownership } & foreign1 & 0.0014647 & -0.0133245 & 0.014442 & 0.0123595 \\
\hline & & (0.0241068) & $(0.0101307)$ & $(0.0176322)$ & $(0.0106151)$ \\
\hline \multirow[t]{2}{*}{ firm size class } & size & -0.0003255 & & $-0.0249^{* * *}$ & $-0.0152^{* * *}$ \\
\hline & & (0.0099629) & & $(0.0063326)$ & (0.0038975) \\
\hline \multirow[t]{2}{*}{ age of firm } & age & -0.0003877 & $-0.0005542 * * *$ & 0.0002555 & \\
\hline & & $(0.0004337)$ & $(0.000211)$ & $(0.0003898)$ & \\
\hline \multirow{2}{*}{ manager experience } & mgrexp & -0.000051 & & -0.0000169 & \\
\hline & & $(0.0007017)$ & & $(0.0004239)$ & \\
\hline \multirow[t]{2}{*}{ local markets } & local & 0.002545 & & -0.0243746 & $0.0291 *$ \\
\hline & & $(0.0383105)$ & & $(0.0280806)$ & $(0.0154731)$ \\
\hline \multirow[t]{2}{*}{ national markets } & national & 0.0050136 & & -0.0183832 & $0.0281 *$ \\
\hline & & $(0.035424)$ & & $(0.0261293)$ & $(0.0164919)$ \\
\hline \multirow[t]{2}{*}{ exports (\% of sales) } & export & -0.0002489 & & -0.0004191 & $0.0003^{* *}$ \\
\hline & & $(0.0004363)$ & & $(0.000303)$ & $(0.0001522)$ \\
\hline \multirow[t]{2}{*}{ female owner } & femown & -0.0180026 & & -0.0016191 & \\
\hline & & $(0.014538)$ & & $(0.0084441)$ & \\
\hline \multirow[t]{2}{*}{ female manager } & femman & -0.0140865 & & -0.0018959 & \\
\hline & & $(0.0181427)$ & & $(0.0099676)$ & \\
\hline \multirow[t]{2}{*}{$\%$ of workers with degrees } & degree & -0.0000481 & & 0.0000232 & \\
\hline & & $(0.0003597)$ & & $(0.0001515)$ & \\
\hline \multirow[t]{2}{*}{ sales per worker } & spw & $-1.42 \mathrm{E}-08$ & $-0.000000007^{* * *}$ & $-1.61 \mathrm{E}-08$ & \\
\hline & & $(0.000000027)$ & $(0.00000000136)$ & $(0.0000000249)$ & \\
\hline \multirow[t]{2}{*}{ profit per worker } & ppw & $-3.06 \mathrm{E}-08$ & $0.000000007^{* * *}$ & $1.61 \mathrm{E}-08$ & \\
\hline & & $(0.0000000497)$ & $(0.00000000136)$ & (0.0000000249) & \\
\hline growth in sales & growth & 0.0000234 & & $0.00000001^{*}$ & \\
\hline & & $(0.0000177)$ & & $(0.00000000617)$ & \\
\hline infrastructure obstacles & infra & 0.0003862 & $0.0067^{* *}$ & -0.0043241 & \\
\hline & & $(0.0064015)$ & $(0.0028932)$ & (0.0041419) & \\
\hline bureaucratic obstacles & burcy & $0.0526^{* * *}$ & $0.0534 * * *$ & $0.0339 * * *$ & $0.0231^{* * *}$ \\
\hline & & (0.0091853) & $(0.0039932)$ & $(0.0062238)$ & $(0.0040531)$ \\
\hline polity obstacles & polity & -0.00000214 & & $0.0210^{* * *}$ & $0.0169 * * *$ \\
\hline & & $(0.0000269)$ & & $(0.0052245)$ & $(0.0035794)$ \\
\hline bid for government work & govtbid & 0.0253938 & $0.0461^{* * *}$ & 0.0067534 & $0.0126^{*}$ \\
\hline & & $(0.0185547)$ & $(0.0090631)$ & $(0.009708)$ & $(0.006865)$ \\
\hline Country level variables: & & & & & \\
\hline gdp per capita & gdpcap & -0.00000629 & $-0.000010 * * *$ & $-0.00002 * * *$ & $-0.00001 * * *$ \\
\hline & & $(0.00000548)$ & $(0.00000256)$ & $(0.00000388)$ & $(0.00000131)$ \\
\hline regulatory efficiency & regeff & -0.0029837 & & $-0.0076^{* * *}$ & \\
\hline & & $(0.0031865)$ & & $(0.0023964)$ & \\
\hline secondary school enrolment & edsecond & $0.0037^{*}$ & $0.0027^{* * *}$ & $-0.0034^{* * *}$ & $-0.0013^{* * *}$ \\
\hline & & $(0.002133)$ & $(0.0006382)$ & $(0.0007758)$ & $(0.0003358)$ \\
\hline tertiary education enrolment & edtertiary & -0.0030105 & & $0.0034^{* * *}$ & \\
\hline & & $(0.0021654)$ & & $(0.0010624)$ & \\
\hline new business starts & enterprise & -0.0254245 & $-0.0316^{* * *}$ & 0.0024366 & \\
\hline & & $(0.0172165)$ & $(0.009447)$ & $(0.0068784)$ & \\
\hline natural resource rents & natresrents & 0.0000713 & & $0.0072^{* * *}$ & \\
\hline & & $(0.0036711)$ & & $(0.0019057)$ & \\
\hline trade openness & tradeopen & 0.0007433 & & $0.0027^{* * *}$ & $0.0042^{* * *}$ \\
\hline & & $(0.0012497)$ & & $(0.0005291)$ & $(0.0003043)$ \\
\hline country dummy variables & & yes & yes & yes & yes \\
\hline Number of observations & & 2249 & 12523 & 6151 & 14316 \\
\hline LR chi2 $2(42)$ & & 275.06 & 1405.23 & 518.63 & 1606.16 \\
\hline Prob > chi2 & & 0 & 0 & 0 & 0 \\
\hline Log likelihood & & -876.05201 & -5136.2637 & -2075.8909 & -4741.5728 \\
\hline Pseudo R2 & & 0.1357 & 0.1203 & 0.111 & 0.1448 \\
\hline
\end{tabular}




\begin{tabular}{|c|c|c|c|c|c|c|c|c|c|}
\hline \multicolumn{5}{|c|}{ TABLE 2: TWO-STEP PROBIT WITH ENDOGENOUS REG RESSORS } & & & & & \\
\hline \multicolumn{2}{|c|}{ SAMPLE 1 (2009-2010) } & & & & SAMPLE $2(2013$ & 3-2015) & & & \\
\hline \multicolumn{5}{|c|}{ First step regression (endogenous variable $=$ foreign) } & \multicolumn{5}{|c|}{ First step regression (endogenous variable = foreign) } \\
\hline & Coef. & Std. Err. & $\mathbf{t}$ & $\mathrm{P}>\mathrm{t}$ & & Coef. & Std. Err. & t & $P>t$ \\
\hline licansing & $4.147076^{* * *}$ & 0.43033 & 9.64 & 0.000 & licansing & $4.942706^{* * *}$ & 0.44367 & 11.14 & 0.000 \\
\hline size & $2.857678^{* * *}$ & 0.20819 & 13.73 & 0.000 & size & $3.175611^{* * *}$ & 0.21493 & 14.77 & 0.000 \\
\hline femown & $-0.7001542^{* *}$ & 0.33663 & -2.08 & 0.038 & burcy & $0.5188671^{* *}$ & 0.25633 & 2.02 & 0.043 \\
\hline burcy & $0.545719^{* *}$ & 0.24795 & 2.2 & 0.028 & polity & -0.17623 & 0.22213 & -0.79 & 0.428 \\
\hline polity & -0.21881 & 0.21480 & -1.02 & 0.308 & govtbid & $-1.007452^{* *}$ & 0.42000 & -2.4 & 0.016 \\
\hline gdpcapita & $0.0000929 * *$ & 0.00004 & 2.18 & 0.029 & gdpcapita & $0.0001895^{* * *}$ & 0.00004 & 4.34 & 0.000 \\
\hline edsecond & -0.01407 & 0.01178 & -1.19 & 0.232 & edsecond & -0.01208 & 0.01222 & -0.99 & 0.323 \\
\hline edtertiary & $-0.037645^{* * *}$ & 0.01141 & -3.3 & 0.001 & edtertiary & $-0.0493541 * * *$ & 0.01178 & -4.19 & 0.000 \\
\hline natresrents & $-0.1045021^{* * *}$ & 0.01613 & -6.48 & 0.000 & natresrents & $-0.1207616^{* * *}$ & 0.01664 & -7.26 & 0.000 \\
\hline constant & $3.228381^{* * *}$ & 0.95600 & 3.38 & 0.001 & constant & $2.553279 * * *$ & 0.99393 & 2.57 & 0.010 \\
\hline \multicolumn{2}{|c|}{ Number of observations } & 14992 & & & \multicolumn{2}{|c|}{ Number of observations } & 14,963 & & \\
\hline$F(9,14982)$ & & 45.830 & & & $F(9,14953)$ & & 54.640 & & \\
\hline Prob $>F$ & & 0.000 & & & Prob > F & & 0.000 & & \\
\hline R-squared & & 0.027 & & & R-squared & & 0.032 & & \\
\hline Adj R-squared & & 0.026 & & & Adj R-squared & & 0.031 & & \\
\hline \multicolumn{5}{|c|}{ Second step - probit, dependent variable $=$ bribe $(0,1)$} & \multicolumn{5}{|c|}{ Second step - probit, dependent variable $=$ bribe $(0,1)$} \\
\hline & Coef. & Std. Err. & z & $P>Z$ & & Coef. & Std. Err. & z & P>Z \\
\hline foreign & 0.01235 & 0.00886 & 1.39 & 0.163 & foreign & 0.01011 & 0.00741 & 1.36 & 0.173 \\
\hline size & $-0.0732883 * *$ & 0.03259 & -2.25 & 0.025 & size & $-0.0754886 * *$ & 0.03110 & -2.43 & 0.015 \\
\hline femown & $0.091903^{* * *}$ & 0.02973 & 3.09 & 0.002 & burcy & $0.1376875^{* * *}$ & 0.02084 & 6.61 & 0.000 \\
\hline burcy & $0.1349797^{* * *}$ & 0.02109 & 6.4 & 0.000 & polity & $0.0979363^{* * *}$ & 0.01766 & 5.55 & 0.000 \\
\hline polity & $0.1006286^{* * *}$ & 0.01771 & 5.68 & 0.000 & govtbid & $0.0980295^{* * *}$ & 0.03425 & 2.86 & 0.004 \\
\hline gdpcapita & $-0.0000429 * * *$ & 0.00000 & -11.28 & 0.000 & gdpcapita & $-0.0000451^{* * *}$ & 0.00000 & -11.46 & 0.000 \\
\hline edsecond & $-0.0116734 * * *$ & 0.00104 & -11.28 & 0.000 & edsecond & $-0.0110623 * * *$ & 0.00103 & -10.69 & 0.000 \\
\hline edtertiary & $0.0122419 * * *$ & 0.00111 & 11.06 & 0.000 & edtertiary & $0.0123098^{* * *}$ & 0.00112 & 10.99 & 0.000 \\
\hline natresrents & $0.0126534^{* * *}$ & 0.00178 & 7.09 & 0.000 & natresrents & $0.0120955^{* * *}$ & 0.00177 & 6.84 & 0.000 \\
\hline constant & $-0.6659479 * * *$ & 0.08406 & -7.92 & 0.000 & constant & $-0.679189 * * *$ & 0.08118 & -8.37 & 0.000 \\
\hline Wald chi2(9) & & & 631.02 & & Wald chi2(9) & & & 621.41 & \\
\hline Prob >chi2 & & & 0.000 & & Prob > chi2 & & & 0.000 & \\
\hline \multicolumn{3}{|c|}{ Wald test of exogeneity: chi2(1) } & 1.84 & & \multicolumn{3}{|c|}{ Wald test of exogeneity: chi2(1) } & 1.63 & \\
\hline Prob > chi2 & & & 0.1753 & & Prob > chi2 & & & 0.2023 & \\
\hline \multicolumn{2}{|c|}{ Weak instruments tests: } & & & & \multicolumn{2}{|c|}{ Weak instruments tests: } & & & \\
\hline \multicolumn{2}{|c|}{ Null: beta[bribe:foreign] $=0$} & & & & \multicolumn{2}{|c|}{ Null: beta[bribe:foreign] $=0$} & & & \\
\hline Test Statistic & & & p-value & & Test Statistic & & & & p-value \\
\hline \multicolumn{2}{|c|}{ Anderson-Rubin } & $\operatorname{chi} 2(1)=$ & 0.1591 & & \multicolumn{2}{|c|}{ Anderson-Rubin } & $\operatorname{chi} 2(1)=$ & 1.88 & 0.1700 \\
\hline Wald & & $\operatorname{chi} 2(1)=$ & 0.1633 & & Wald & & $\operatorname{chi} 2(1)=$ & 1.86 & 0.1728 \\
\hline
\end{tabular}




\begin{tabular}{|c|c|c|c|c|c|c|c|c|}
\hline \multicolumn{6}{|c|}{ TABLE 3: PROPENSITY SCORE MATCHING USING SAMPLE 1} & \multirow[b]{2}{*}{ T-stat } & \multirow[b]{2}{*}{ Observations } & \\
\hline Variable & Sample & Treated & Controls & Differenci & S.E. & & & \\
\hline \multicolumn{9}{|c|}{ Treatment variable : foreign1 } \\
\hline \multirow[t]{2}{*}{ bribe } & Unmatched & 0.175676 & 0.163786 & 0.01189 & 0.022862 & 0.52 & Untreated & 2,430 \\
\hline & ATT & 0.176871 & 0.170316 & 0.006555 & 0.026833 & 0.24 & Treated & 296 \\
\hline \multicolumn{9}{|c|}{ Treatment variable : foreign 3} \\
\hline \multirow[t]{2}{*}{ bribe } & Unmatched & 0.162791 & 0.163206 & -0.00042 & 0.026312 & 0.02 & Untreated & 2,408 \\
\hline & ATT & 0.162791 & 0.200053 & -0.03726 & 0.031291 & 1.19 & Treated & 215 \\
\hline \multicolumn{9}{|c|}{ Treatment variable : joint venture } \\
\hline \multirow[t]{2}{*}{ bribe } & Unmatched & 0.301587 & 0.162977 & 0.13861 & 0.047407 & $2.92^{* *}$ & Untreated & 2,620 \\
\hline & ATT & 0.290323 & 0.179843 & 0.110479 & 0.059359 & $1.86^{*}$ & Treated & 63 \\
\hline \multicolumn{9}{|c|}{\begin{tabular}{|l|l|l} 
Treatment variable : bureaucracy $(0,1)$ & \\
\end{tabular}} \\
\hline \multirow[t]{2}{*}{ bribe } & Unmatched & 0.176213 & 0.07989 & 0.096324 & 0.020793 & $4.63 * * *$ & Untreated & 2,287 \\
\hline & ATT & 0.176213 & 0.0964 & 0.079814 & 0.029468 & $2.71 * * *$ & Treated & 363 \\
\hline \multicolumn{9}{|c|}{\begin{tabular}{l|l|l|l|l} 
Treatment variable: Government bid & &
\end{tabular}} \\
\hline \multirow[t]{2}{*}{ bribe } & Unmatched & 0.231445 & 0.163803 & 0.067642 & 0.012786 & $5.29 * * *$ & Untreated & 6,134 \\
\hline & ATT & 0.231672 & 0.179993 & 0.051679 & 0.014268 & $3.62 * * *$ & Treated & 1,050 \\
\hline \multicolumn{9}{|c|}{ Treatment variable : polity $(0,1)$} \\
\hline \multirow[t]{2}{*}{ bribe } & Unmatched & 0.198925 & 0.159316 & 0.039609 & 0.008412 & $4.71^{* * *}$ & Untreated & 4,852 \\
\hline & ATT & 0.198925 & 0.143475 & 0.05545 & 0.011122 & $4.99 * * *$ & Treated & 3,534 \\
\hline
\end{tabular}




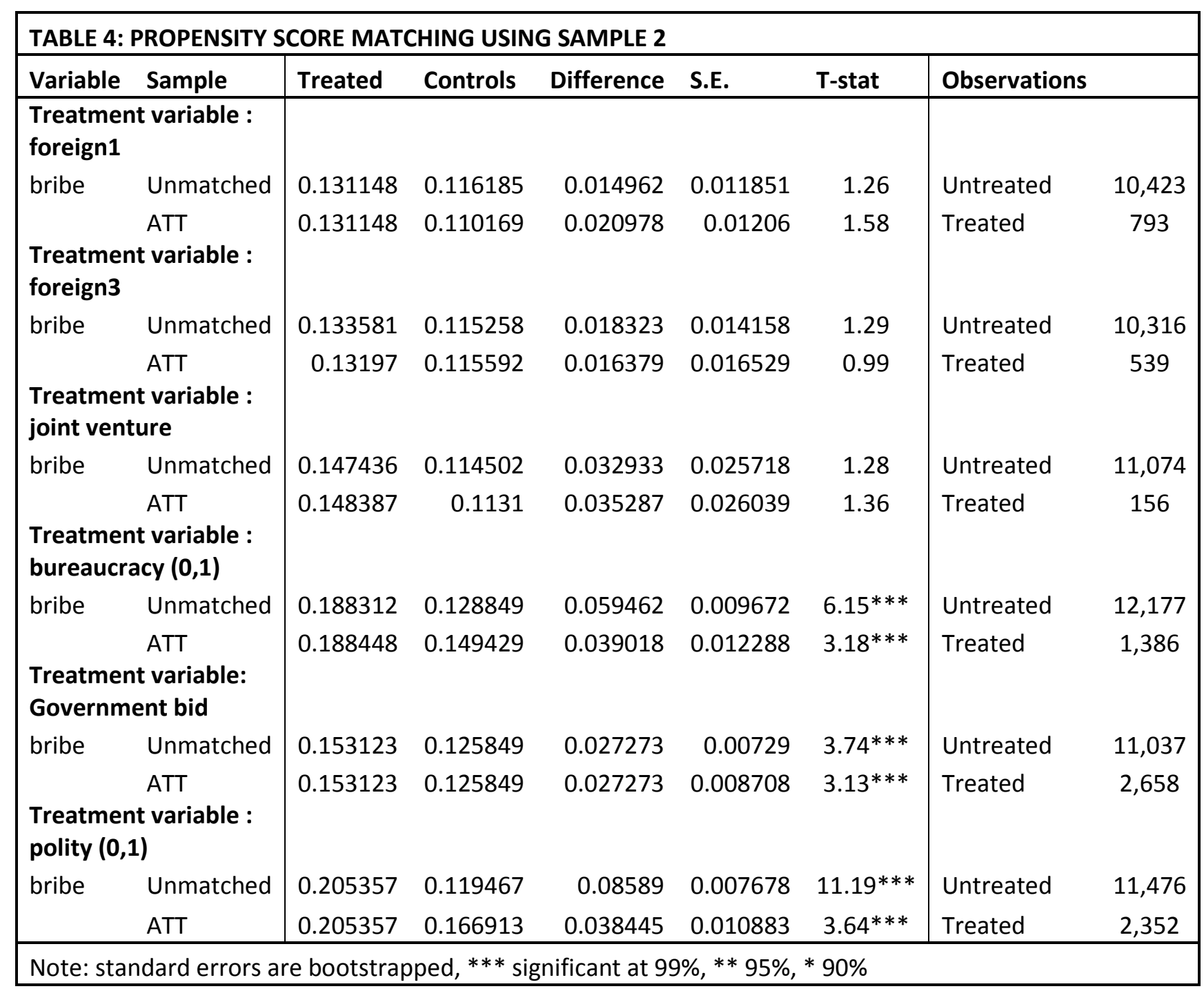




\begin{tabular}{|c|c|c|c|c|}
\hline \multicolumn{5}{|c|}{ Table 5: IPWRA Analysis for Sample 1 (2009-10) } \\
\hline \multirow[b]{2}{*}{ Control Group } & \multicolumn{2}{|l|}{ Treatment Group } & \multirow[b]{2}{*}{ Bureaucracy } & \multirow[b]{2}{*}{ Both } \\
\hline & None & Foreign1 & & \\
\hline \multirow[t]{2}{*}{ None } & - & 0.0254701 & $0.0662496 * * *$ & $0.0745474 * * *$ \\
\hline & & $(0.0227301)$ & $(0.0097647)$ & $(0.0243452)$ \\
\hline Foreign Ownership & -0.0124424 & - & 0.0476071 & 0.0296977 \\
\hline (foreign1) & $(0.0294352)$ & & $(0.0395347)$ & $(0.0314002)$ \\
\hline \multirow[t]{2}{*}{ Bureaucracy an Obstacle } & $-0.0588978 * * *$ & -0.0151998 & - & -0.0040684 \\
\hline & $(0.0112416)$ & $(0.0307986)$ & & $(0.0263499)$ \\
\hline \multirow[t]{3}{*}{ Both } & $-0.0762259 * *$ & -0.0017697 & 0.0065233 & - \\
\hline & $(0.0396438)$ & $(0.0374224)$ & $(0.0315063)$ & \\
\hline & \multicolumn{2}{|l|}{ Treatment Group } & & \\
\hline Control Group & None & Foreign1 & Polity & Both \\
\hline \multirow[t]{2}{*}{ None } & - & $0.0370595^{*}$ & $0.0687005^{* * *}$ & $0.073147^{* * *}$ \\
\hline & & (0.021609) & $(0.0126031)$ & $(0.0285161)$ \\
\hline Foreign Ownership & -0.0387405 & - & -0.0154483 & 0.0147903 \\
\hline (foreign1) & $(0.0263962)$ & & $(0.0446246)$ & (0.0381397) \\
\hline \multirow[t]{2}{*}{ Polity } & -0.0167675 & 0.039966 & - & 0.0095754 \\
\hline & $(0.0144882)$ & $(0.0317785)$ & & $(0.0268444)$ \\
\hline \multirow[t]{3}{*}{ Both } & $0.0491044^{*}$ & 0.0477502 & -0.0017756 & - \\
\hline & $(0.0262753)$ & (0.0396293) & $(0.0307682)$ & \\
\hline & \multicolumn{2}{|l|}{ Treatment Group } & & \\
\hline Control Group & None & Foreign1 & Governmentt Bid & Both \\
\hline \multirow[t]{2}{*}{ None } & - & 0.0162415 & $0.0520692 * * *$ & $0.1026281^{* * *}$ \\
\hline & & $(0.0187467)$ & $(0.0143272)$ & $(0.0387941)$ \\
\hline Foreign Ownership & -0.0224348 & - & 0.0262071 & $0.0867351^{* *}$ \\
\hline (foreign1) & $(0.0221662)$ & & $(0.0263953)$ & $(0.0416359)$ \\
\hline Bid for Government & $-0.0542503 * * *$ & 0.027425 & - & 0.0649752 \\
\hline Contract & $(0.0151866)$ & $(0.0151866)$ & & $(0.0419252)$ \\
\hline \multirow[t]{2}{*}{ Both } & $-0.0925371^{*}$ & $-0.1003095^{* *}$ & -0.0398889 & - \\
\hline & (0.0519179) & $(0.0485625)$ & (0.0503048) & \\
\hline
\end{tabular}




\begin{tabular}{|c|c|c|c|c|}
\hline \multicolumn{5}{|c|}{ Table 6: IPWRA Analysis for Sample 2 (2013-15) } \\
\hline \multirow[b]{2}{*}{ Control Group } & \multicolumn{2}{|l|}{ Treatment Group } & \multirow[b]{2}{*}{ Bureaucracy } & \multirow[b]{2}{*}{ Both } \\
\hline & None & Foreign1 & & \\
\hline \multirow[t]{2}{*}{ None } & - & 0.0060622 & $0.0818743^{* * *}$ & $0.1783046^{* * *}$ \\
\hline & & $(0.012927)$ & $(0.0092697)$ & $(0.0371229)$ \\
\hline Foreign Ownership & 0.0074532 & - & $0.0902489 * * *$ & $0.1681178 * * *$ \\
\hline (foreign1) & $(0.0164054)$ & & $(0.0175682)$ & $(0.0395061)$ \\
\hline \multirow[t]{2}{*}{ Bureaucracy an Obstacle } & $-0.0893128 * * *$ & $-0.0676008 * * *$ & - & $0.0887312^{* *}$ \\
\hline & $(0.0098249)$ & $(0.0186503)$ & & $(0.040203)$ \\
\hline \multirow[t]{3}{*}{ Both } & $-0.2691205^{* * *}$ & $-0.1574655^{* * *}$ & $-0.1687719 * * *$ & - \\
\hline & $(0.067649)$ & $(0.0387912)$ & $(0.0644569)$ & \\
\hline & \multicolumn{2}{|l|}{ Treatment Group } & & \\
\hline Control Group & None & Foreign1 & Polity & Both \\
\hline \multirow[t]{2}{*}{ None } & - & 0.0056734 & $0.0540383^{* * *}$ & $0.1867473^{* * *}$ \\
\hline & & $(0.0126148)$ & $(0.0112334)$ & $(0.0374443)$ \\
\hline Foreign Ownership & 0.0089766 & - & 0.0330255 & $0.1311705^{* * *}$ \\
\hline (foreign1) & $(0.0152307)$ & & $(0.0306189)$ & $(0.0454263)$ \\
\hline \multirow[t]{2}{*}{ Polity } & $-0.0496246 * * *$ & $-0.0504314^{* *}$ & - & $0.1146705^{* * *}$ \\
\hline & $(0.0130178)$ & $(0.0231308)$ & & (0.0391749) \\
\hline \multirow[t]{3}{*}{ Both } & $-0.2884424 * * *$ & $-0.116596^{* *}$ & $-0.1664501 * * *$ & - \\
\hline & $(0.0841213)$ & $(0.055556)$ & $(0.0620418)$ & \\
\hline & \multicolumn{2}{|l|}{ Treatment Group } & & \\
\hline Control Group & None & Foreign1 & Governmentt Bid & Both \\
\hline \multirow[t]{2}{*}{ None } & - & 0.0224129 & $0.0243541^{* * *}$ & 0.0340775 \\
\hline & & $(0.0138468)$ & $(0.008169)$ & $(0.0276326)$ \\
\hline Foreign Ownership & -0.0060577 & - & 0.0133222 & 0.0115531 \\
\hline (foreign1) & $(0.0176021)$ & & $(0.0184377)$ & $(0.03041)$ \\
\hline Bid for Government & $-0.0199305^{* *}$ & 0.0083291 & - & 0.0137962 \\
\hline Contract & $(0.0082722)$ & $(0.0167475)$ & & $(0.0291011)$ \\
\hline \multirow[t]{2}{*}{ Both } & $-0.1236367^{* *}$ & -0.0324785 & $-0.1043204^{* *}$ & - \\
\hline & $(0.0561414)$ & $(0.0341839)$ & $(0.0508602)$ & \\
\hline
\end{tabular}




\begin{tabular}{|c|c|c|}
\hline \multicolumn{3}{|c|}{ Appendix $1:$ Number of Observations by Country } \\
\hline & Sample 1 & Sample 2 \\
\hline Albania & 175 & 360 \\
\hline Argentina & 1054 & \\
\hline Armenia & 374 & 360 \\
\hline Azerbaijan & 380 & 390 \\
\hline Belarus & 273 & 360 \\
\hline Bhutan & 250 & 253 \\
\hline Bosnia-Herzegovina & 361 & 360 \\
\hline Brazil & 1802 & \\
\hline Bulgaria & 288 & 293 \\
\hline Croatia & 159 & 360 \\
\hline Czech & 250 & 254 \\
\hline DR Congo & 359 & 529 \\
\hline Estonia & 273 & 273 \\
\hline Georgia & 373 & 360 \\
\hline Hungary & 291 & 310 \\
\hline Indonesia & 1444 & 1320 \\
\hline Kazakhstan & 544 & 600 \\
\hline Kosovo & 270 & 202 \\
\hline Kyrgyzstan & 235 & 270 \\
\hline Latvia & 271 & 336 \\
\hline Lithuania & 276 & 270 \\
\hline Macedonia & 366 & 360 \\
\hline Madagascar & 445 & 532 \\
\hline Malawi & 150 & 523 \\
\hline Mexico & 1480 & \\
\hline Moldova & 363 & 360 \\
\hline Mongolia & 362 & 360 \\
\hline Montenegro & 116 & 150 \\
\hline Nepal & 486 & 482 \\
\hline Nigeria & 6314 & 2676 \\
\hline Poland & 455 & 542 \\
\hline Romania & 541 & 540 \\
\hline Russia & 1004 & 4220 \\
\hline Serbia & 388 & 360 \\
\hline Slovakia & 275 & 268 \\
\hline Slovenia & 276 & 270 \\
\hline Tajikistan & 360 & 359 \\
\hline Turkey & 1152 & 1344 \\
\hline Ukraine & 851 & 1002 \\
\hline Uzbekistan & 366 & 390 \\
\hline Vietnam & 1053 & 996 \\
\hline TOTAL & 26505 & 23194 \\
\hline
\end{tabular}




\begin{tabular}{|c|c|c|c|c|c|c|c|c|c|c|}
\hline & \multirow[t]{3}{*}{ Observations } & \multicolumn{3}{|c|}{ Number of full time employees } & \multicolumn{3}{|l|}{ Sample Mean } & \multicolumn{3}{|c|}{ Mean score of perceived obstacles } \\
\hline & & & & & $\%$ foreign & $\%$ of sales & Age of & (scored 0-4) & & \\
\hline & & Mean & Maximum & Minimum & ownership & exported & firm (years) & Corruption & Infrastructure & Bureaucracy \\
\hline Tobacco products & 3 & 357 & 658 & 206 & 0.0 & 21.0 & 24.3 & 1.33 & 2.17 & 1.50 \\
\hline Textiles & 852 & 158 & 3200 & 0 & 9.3 & 23.5 & 20.2 & 1.72 & 1.35 & 1.36 \\
\hline Garments & 1755 & 128 & 7400 & 0 & 6.8 & 19.4 & 16.9 & 1.95 & 1.71 & 1.35 \\
\hline Leather & 169 & 149 & 6150 & 2 & 4.5 & 11.9 & 19.0 & 2.53 & 1.93 & 2.12 \\
\hline Wood products & 224 & 49 & 2650 & 0 & 1.2 & 5.3 & 15.8 & 1.94 & 2.56 & 0.94 \\
\hline Paper products & 35 & 132 & 757 & 4 & 1.1 & 10.8 & 17.4 & 1.33 & 1.62 & 0.74 \\
\hline Printing and publishing & 290 & 19 & 272 & 2 & 0.5 & 1.1 & 19.0 & 2.03 & 2.85 & 1.08 \\
\hline Chemicals & 970 & 129 & 3066 & 0 & 10.8 & 11.1 & 24.8 & 1.98 & 1.76 & 1.63 \\
\hline Plastics and rubber & 556 & 117 & 2000 & 0 & 11.7 & 11.7 & 19.7 & 1.73 & 1.85 & 1.18 \\
\hline Mineral Products & 1163 & 80 & 4585 & 0 & 3.8 & 7.7 & 16.1 & 1.56 & 1.89 & 1.03 \\
\hline Basic metals & 184 & 297 & 17167 & 1 & 8.9 & 15.2 & 18.5 & 1.41 & 2.18 & 1.30 \\
\hline Metal products & 1227 & 62 & 2300 & 0 & 6.9 & 10.0 & 17.1 & 1.77 & 2.13 & 1.25 \\
\hline Machinery & 1041 & 117 & 4000 & 0 & 9.5 & 15.1 & 23.2 & 2.23 & 1.74 & 1.70 \\
\hline Electronics & 7 & 162 & 755 & 6 & 14.3 & 20.3 & 16.6 & 0.86 & 1.43 & 0.68 \\
\hline Vehicles & 163 & 217 & 4100 & 3 & 13.7 & 9.2 & 24.6 & 2.73 & 2.68 & 3.34 \\
\hline Other transport equipment & 14 & 279 & 2000 & 22 & 7.9 & 14.3 & 16.4 & 1.36 & 1.21 & 0.81 \\
\hline Furniture, jewellery, games & 844 & 27 & 1225 & 1 & 0.6 & 2.2 & 16.8 & 1.92 & 2.64 & 1.40 \\
\hline Other manufacturing & 1922 & 114 & 20843 & 0 & 9.5 & 14.6 & 19.8 & 1.74 & 1.63 & 1.32 \\
\hline Recycling & 4 & 164 & 182 & 145 & 50.0 & 100.0 & 9.5 & 2.00 & 3.00 & 1.63 \\
\hline Construction & 1198 & 126 & 5133 & 0 & 4.0 & 3.7 & 16.4 & 1.79 & 1.30 & 1.10 \\
\hline Vehicle maintenance & 454 & 62 & 4225 & 0 & 5.7 & 3.9 & 15.8 & 1.74 & 1.42 & 1.25 \\
\hline Wholesale & 1146 & 76 & 4000 & 0 & 11.0 & 8.5 & 14.3 & 1.86 & 1.41 & 1.19 \\
\hline Retail & 3749 & 84 & 20500 & 0 & 5.8 & 3.0 & 14.8 & 1.82 & 1.55 & 1.23 \\
\hline Hotels and restaurants & 529 & 49 & 930 & 0 & 7.3 & 4.4 & 15.8 & 1.75 & 1.39 & 1.10 \\
\hline Land transport & 674 & 224 & 37772 & 0 & 9.3 & 18.1 & 17.4 & 1.84 & 1.37 & 1.22 \\
\hline Water Transport & 4 & 147 & 320 & 22 & 20.5 & 1.3 & 17.5 & 1.00 & 1.25 & 1.31 \\
\hline Support transport services & 8 & 72 & 230 & 1 & 16.1 & 1.0 & 15.3 & 0.60 & 1.35 & 0.83 \\
\hline IT services & 362 & 115 & 5500 & 1 & 9.4 & 7.8 & 14.5 & 2.24 & 1.77 & 1.63 \\
\hline SAMPLE & 26505 & 102 & 37772 & 0 & 6.5 & 8.6 & 17.2 & 1.90 & 1.82 & 1.31 \\
\hline
\end{tabular}




\begin{tabular}{|c|c|c|c|c|c|c|c|c|c|c|}
\hline \multicolumn{11}{|c|}{ Appendix 3: Sample 2 - Selected Characteristics by Sector } \\
\hline & \multirow[t]{3}{*}{ Observations } & \multicolumn{3}{|c|}{ Number of full time employees } & \multicolumn{3}{|l|}{ Sample Mean } & \multicolumn{3}{|c|}{ Mean score of perceived obstacles } \\
\hline & & & & & \% foreign & $\%$ of sales & Age of & (scored 0-4) & & \\
\hline & & Mean & Maximum & Minimum & ownership & exported & firm (years) & Corruption & Infrastructure & Bureaucracy \\
\hline Food manufacture & 1764 & 133 & 12467 & 0 & 5.7 & 12.9 & 17.5 & 1.19 & 1.11 & 0.75 \\
\hline Tobacco products & 49 & 157 & 900 & 1 & 12.6 & 23.0 & 19.0 & 1.07 & 1.19 & 0.94 \\
\hline Textiles & 571 & 146 & 5033 & 0 & 4.6 & 22.5 & 17.7 & 1.12 & 1.01 & 0.80 \\
\hline Garments & 1091 & 129 & 9125 & 0 & 6.0 & 26.4 & 15.6 & 1.32 & 0.98 & 0.76 \\
\hline Leather & 142 & 137 & 2017 & 0 & 7.8 & 35.8 & 15.4 & 1.23 & 1.33 & 0.96 \\
\hline Paper products & 95 & 77 & 1200 & 0 & 8.7 & 11.4 & 15.9 & 1.24 & 1.15 & 0.82 \\
\hline Printing and publishing & 576 & 29 & 410 & 0 & 3.9 & 5.6 & 16.5 & 1.47 & 1.17 & 0.73 \\
\hline Fuels & 27 & 86 & 601 & 2 & 23.0 & 26.2 & 26.9 & 1.81 & 1.12 & 0.88 \\
\hline Chemicals & 643 & 138 & 5869 & 0 & 9.9 & 17.3 & 19.1 & 1.24 & 1.15 & 0.91 \\
\hline Plastics and rubber & 527 & 116 & 17000 & 0 & 6.7 & 9.8 & 16.5 & 1.24 & 1.29 & 0.88 \\
\hline Mineral Products & 1179 & 107 & 7000 & 0 & 5.4 & 12.7 & 17.2 & 1.34 & 1.08 & 0.75 \\
\hline Basic metals & 169 & 80 & 2530 & 0 & 10.1 & 19.7 & 16.9 & 1.53 & 1.18 & 0.87 \\
\hline Metal products & 1003 & 64 & 2450 & 0 & 3.9 & 17.0 & 15.7 & 1.27 & 1.05 & 0.81 \\
\hline Machinery & 590 & 87 & 6001 & 0 & 7.8 & 15.5 & 17.0 & 1.36 & 0.84 & 0.75 \\
\hline Electrical machinery & 263 & 114 & 3500 & 3 & 7.1 & 11.8 & 16.5 & 1.34 & 0.85 & 0.78 \\
\hline Electronics & 33 & 150 & 1636 & 3 & 10.6 & 18.0 & 16.9 & 1.06 & 1.09 & 0.69 \\
\hline Vehicles & 184 & 80 & 3500 & 2 & 3.1 & 10.8 & 15.3 & 1.26 & 0.88 & 0.85 \\
\hline Other transport equipment & 59 & 152 & 2640 & 5 & 9.0 & 21.8 & 20.5 & 1.05 & 0.90 & 0.82 \\
\hline Furniture, jewellery, games & 642 & 42 & 2000 & 0 & 3.9 & 12.7 & 14.8 & 1.49 & 1.26 & 0.92 \\
\hline Other manufacturing & 86 & 37 & 362 & 3 & 2.8 & 16.4 & 16.4 & 0.63 & 1.16 & 1.04 \\
\hline Recycling & 47 & 68 & 970 & 5 & 6.0 & 12.9 & 15.7 & 1.49 & 1.35 & 1.15 \\
\hline Construction & 1472 & 71 & 3000 & 0 & 2.6 & 3.2 & 14.1 & 1.36 & 0.82 & 0.72 \\
\hline Vehicle maintenance & 657 & 36 & 3897 & 0 & 4.2 & 5.8 & 14.4 & 1.48 & 1.09 & 0.87 \\
\hline Wholesale & 2715 & 39 & 7050 & 0 & 4.7 & 5.1 & 12.0 & 1.36 & 1.00 & 0.76 \\
\hline Retail & 4551 & 45 & 9850 & 0 & 4.2 & 4.3 & 14.5 & 1.17 & 0.94 & 0.77 \\
\hline Hotels and restaurants & 1033 & 33 & 1117 & 0 & 3.6 & 5.5 & 14.1 & 1.30 & 1.09 & 0.78 \\
\hline Land transport & 508 & 99 & 17000 & 0 & 6.2 & 18.3 & 15.4 & 1.48 & 0.96 & 0.87 \\
\hline Water Transport & 3 & 119 & 290 & 7 & 0.0 & 10.0 & 19.0 & 2.00 & 0.44 & 0.50 \\
\hline Air Transport & 5 & 53 & 200 & 0 & 4.0 & 46.0 & 17.3 & 2.40 & 1.87 & 1.40 \\
\hline Support transport services & 305 & 70 & 4100 & 0 & 6.4 & 13.4 & 13.5 & 1.16 & 0.93 & 0.67 \\
\hline Post and telecommunications & 170 & 65 & 1150 & 0 & 7.3 & 3.6 & 13.2 & 1.43 & 1.09 & 0.77 \\
\hline IT services & 280 & 24 & 330 & 0 & 6.4 & 10.0 & 11.1 & 1.41 & 1.13 & 0.80 \\
\hline
\end{tabular}




\section{Questions relating to bribery:}

In reference to that application for an electrical connection, was an informal gift or payment expected or requested?

In reference to that application for a water connection, was an informal gift or payment expected or requested?

In any of these [tax] inspections or meetings was a gift or informal payment expected or requested?

Percent of the[government] contract value paid as informal payments or gifts

In reference to that application for an import license, was an informal gift or payment expected or requested?

In reference to that application for an operating license, was an informal gift or payment expected or requested?

Total annual cost of informal payments*

*It is said that establishments are sometimes required to make gifts or informal payments to public officials to "get things done"

with regard to customs, taxes, licenses, regulations, services etc. On average, what percent of

total annual sales, or estimated total annual value, do establishments like this one pay in informal payments or gifts to public officials

for this purpose?

\section{Related questions with high "no response" rates:}

Length of wait for an electrical connection

Average number of incidents of water insufficiency per month

Number of times inspected by or met with tax officials

Over the last year, has this establishment secured or attempted to secure a government contract?

Approximately how many days did it take to obtain this import license from the day of the application to the day it was granted?

Approximately how many days did it take to obtain this operating license from the day of the application to the day it was granted?

\section{All questions (\% of sample);}

percentage of sample:

no response don't know

(blank entry)

$83.8 \%$

\begin{tabular}{|c|c|}
\hline $83.8 \%$ & 0.36 \\
\hline $92.2 \%$ & 0.20 \\
\hline $39.9 \%$ & 1.2 \\
\hline $67.5 \%$ & 2.36 \\
\hline $79.1 \%$ & 0.32 \\
\hline $90.1 \%$ & 0.58 \\
\hline $1.2 \%$ & \\
\hline
\end{tabular}

percentage of sample:

no response

$83.99 \%$

$93.94 \%$

$40.16 \%$

$17.58 \%$

$92.03 \%$

$81.03 \%$

percentage of sample:

percentage of

(blank entry)

minimum

maximum

mean

$0.03 \%$

$98.05 \%$

$38.43 \%$ percentage of responses*

don't know refuse

rense

\begin{tabular}{|l|l|l|l|}
\hline & & & \\
\hline $0.36 \%$ & $0.19 \%$ & $2.24 \%$ & $1.19 \%$ \\
\hline $0.20 \%$ & $0.12 \%$ & $2.52 \%$ & $1.54 \%$ \\
\hline $1.20 \%$ & $1.79 \%$ & $1.99 \%$ & $2.98 \%$ \\
\hline $2.36 \%$ & $1.47 \%$ & $7.25 \%$ & $4.52 \%$ \\
\hline $0.32 \%$ & $0.24 \%$ & $3.27 \%$ & $2.38 \%$ \\
\hline $0.58 \%$ & $0.57 \%$ & $2.78 \%$ & $2.73 \%$ \\
\hline $9.8 \%$ & $6.7 \%$ & $9.9 \%$ & $6.8 \%$ \\
\hline & & & \\
\hline
\end{tabular}

Note: for the purposes of calculation "no response" is a blank entry; "don't knows" and "refuse to answer" are treated as responses in these calculations 


\begin{tabular}{|c|c|c|c|c|c|}
\hline \multicolumn{3}{|c|}{ Appendix 5: Analysis by country of responses to bribery question } & & & \\
\hline \multicolumn{6}{|c|}{ It is said that establishments are sometimes required to make gifts or informal payments to public officials to "get things done" } \\
\hline \multicolumn{6}{|c|}{ with regard to customs, taxes, licenses, regulations, services etc. On average, what percent of total annual sales, or estimated } \\
\hline \multicolumn{6}{|c|}{ total annual value, do establishments like this one pay in informal payments or gifts to public officials for this purpose? } \\
\hline \multirow[t]{2}{*}{ Country } & Proprtion of respondents* & Respondents* & no respone & refused to answer & don't know \\
\hline & who paid a bribe & & (blank entry) & & \\
\hline Albania & $12.9 \%$ & $72.3 \%$ & $0.0 \%$ & $11.2 \%$ & $16.4 \%$ \\
\hline Argentina & $13.8 \%$ & $85.3 \%$ & $0.0 \%$ & $0.6 \%$ & $14.1 \%$ \\
\hline Armenia & $7.3 \%$ & $94.6 \%$ & $0.0 \%$ & $3.4 \%$ & $2.0 \%$ \\
\hline Azerbaijan & $14.3 \%$ & $80.6 \%$ & $0.0 \%$ & $14.9 \%$ & $4.4 \%$ \\
\hline Belarus & $7.9 \%$ & $87.5 \%$ & $0.0 \%$ & $7.3 \%$ & $5.2 \%$ \\
\hline Bhutan & $3.2 \%$ & $98.6 \%$ & $0.0 \%$ & $0.4 \%$ & $1.0 \%$ \\
\hline Bosnia-Herzegovina & $7.2 \%$ & $89.0 \%$ & $0.0 \%$ & $2.2 \%$ & $8.7 \%$ \\
\hline Brazil & $12.8 \%$ & $91.3 \%$ & $0.0 \%$ & $1.6 \%$ & $7.0 \%$ \\
\hline Bulgaria & $10.1 \%$ & $73.1 \%$ & $0.0 \%$ & $8.1 \%$ & $18.8 \%$ \\
\hline Croatia & $11.3 \%$ & $88.4 \%$ & $0.0 \%$ & $1.5 \%$ & $10.0 \%$ \\
\hline Czech & $9.6 \%$ & $86.9 \%$ & $0.0 \%$ & $4.2 \%$ & $8.9 \%$ \\
\hline DR Congo & $44.8 \%$ & $77.7 \%$ & $3.7 \%$ & $10.0 \%$ & $8.6 \%$ \\
\hline Estonia & $1.6 \%$ & $82.1 \%$ & $0.0 \%$ & $2.4 \%$ & $15.6 \%$ \\
\hline Georgia & $1.4 \%$ & $85.4 \%$ & $0.0 \%$ & $4.4 \%$ & $10.2 \%$ \\
\hline Hungary & $6.5 \%$ & $84.2 \%$ & $0.0 \%$ & $12.6 \%$ & $3.2 \%$ \\
\hline Indonesia & $15.6 \%$ & $84.4 \%$ & $0.0 \%$ & $8.3 \%$ & $7.3 \%$ \\
\hline Kazakhstan & $16.6 \%$ & $81.4 \%$ & $0.0 \%$ & $10.8 \%$ & $7.9 \%$ \\
\hline Kosovo & $10.7 \%$ & $85.0 \%$ & $0.0 \%$ & $3.0 \%$ & $12.1 \%$ \\
\hline Kyrgyzstan & $40.2 \%$ & $79.8 \%$ & $0.0 \%$ & $7.9 \%$ & $12.3 \%$ \\
\hline Latvia & $5.9 \%$ & $72.5 \%$ & $0.0 \%$ & $2.5 \%$ & $25.0 \%$ \\
\hline Lithuania & $8.3 \%$ & $87.9 \%$ & $0.0 \%$ & $4.2 \%$ & $7.9 \%$ \\
\hline Macedonia & $9.1 \%$ & $88.0 \%$ & $0.0 \%$ & $2.6 \%$ & $9.4 \%$ \\
\hline Madagascar & $21.3 \%$ & $43.8 \%$ & $56.2 \%$ & $0.0 \%$ & $0.0 \%$ \\
\hline Malawi & $10.0 \%$ & $83.5 \%$ & $0.0 \%$ & $6.4 \%$ & $10.1 \%$ \\
\hline Mexico & $10.0 \%$ & $98.1 \%$ & $0.0 \%$ & $0.3 \%$ & $1.6 \%$ \\
\hline Moldova & $13.1 \%$ & $82.6 \%$ & $0.0 \%$ & $7.1 \%$ & $10.4 \%$ \\
\hline Mongolia & $30.0 \%$ & $90.9 \%$ & $0.0 \%$ & $3.7 \%$ & $5.4 \%$ \\
\hline Montenegro & $10.0 \%$ & $83.1 \%$ & $0.0 \%$ & $3.8 \%$ & $13.2 \%$ \\
\hline Nepal & $12.5 \%$ & $91.4 \%$ & $0.0 \%$ & $4.5 \%$ & $4.0 \%$ \\
\hline Nigeria & $51.4 \%$ & $90.8 \%$ & $0.0 \%$ & $7.8 \%$ & $1.3 \%$ \\
\hline Poland & $8.0 \%$ & $81.9 \%$ & $0.0 \%$ & $8.1 \%$ & $9.9 \%$ \\
\hline Romania & $12.2 \%$ & $80.2 \%$ & $0.0 \%$ & $5.5 \%$ & $14.3 \%$ \\
\hline Russia & $15.5 \%$ & $78.9 \%$ & $0.0 \%$ & $7.8 \%$ & $13.2 \%$ \\
\hline Serbia & $16.6 \%$ & $78.3 \%$ & $0.0 \%$ & $1.9 \%$ & $19.8 \%$ \\
\hline Slovakia & $8.9 \%$ & $82.9 \%$ & $0.0 \%$ & $7.7 \%$ & $9.4 \%$ \\
\hline Slovenia & $8.9 \%$ & $90.1 \%$ & $0.0 \%$ & $0.7 \%$ & $9.2 \%$ \\
\hline Tajikistan & $29.4 \%$ & $74.8 \%$ & $0.0 \%$ & $12.1 \%$ & $13.1 \%$ \\
\hline Turkey & $7.3 \%$ & $92.6 \%$ & $0.0 \%$ & $3.6 \%$ & $3.8 \%$ \\
\hline Ukraine & $34.6 \%$ & $39.8 \%$ & $0.0 \%$ & $6.1 \%$ & $54.1 \%$ \\
\hline Uzbekistan & $26.7 \%$ & $91.7 \%$ & $0.0 \%$ & $4.5 \%$ & $3.8 \%$ \\
\hline Vietnam & $47.2 \%$ & $56.1 \%$ & $0.0 \%$ & $23.5 \%$ & $20.4 \%$ \\
\hline FULL SAMPLE & $22.4 \%$ & $82.3 \%$ & $1.2 \%$ & $6.7 \%$ & $9.8 \%$ \\
\hline minimum & $1.4 \%$ & $39.8 \%$ & $0.0 \%$ & $0.0 \%$ & $0.0 \%$ \\
\hline maximum & $51.4 \%$ & $98.6 \%$ & $56.2 \%$ & $23.5 \%$ & $54.1 \%$ \\
\hline
\end{tabular}


APPENDIX 6: CHECKS FOR BIAS ON OBSERVABLES - SAMPLE 1

Treatment variable: foreign 1

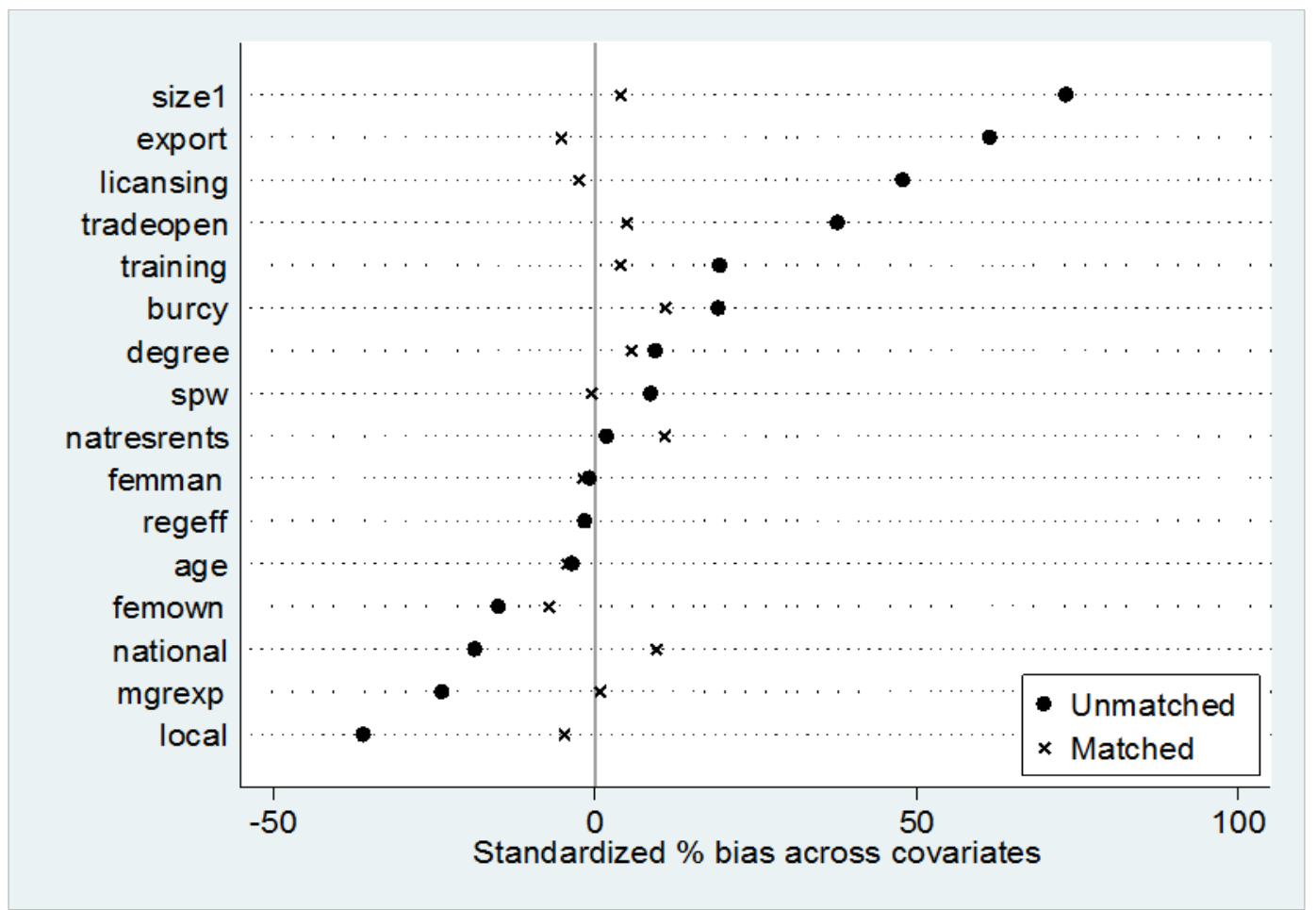

Treatment variable: foreign 3

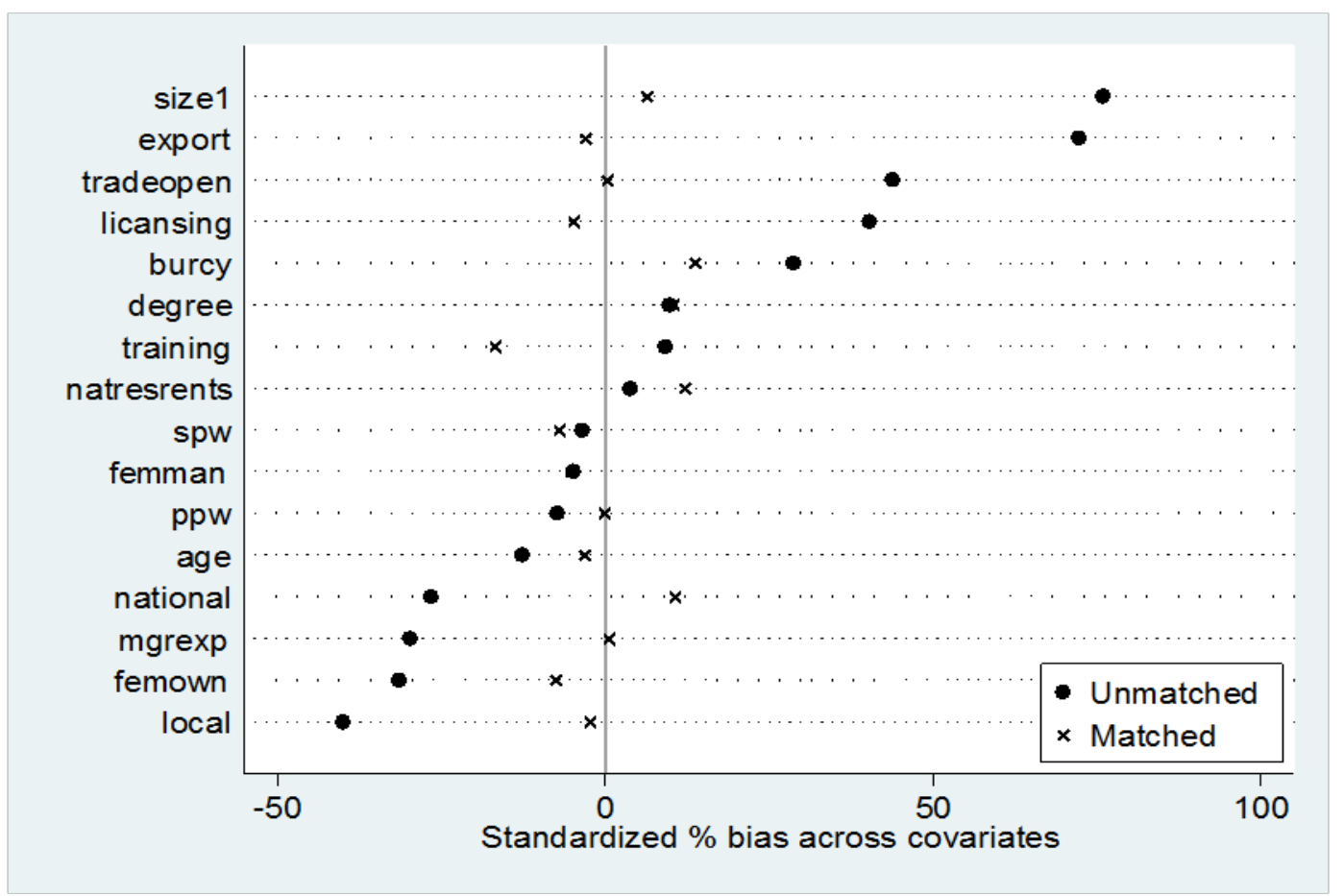


Treatment variable: jointvent

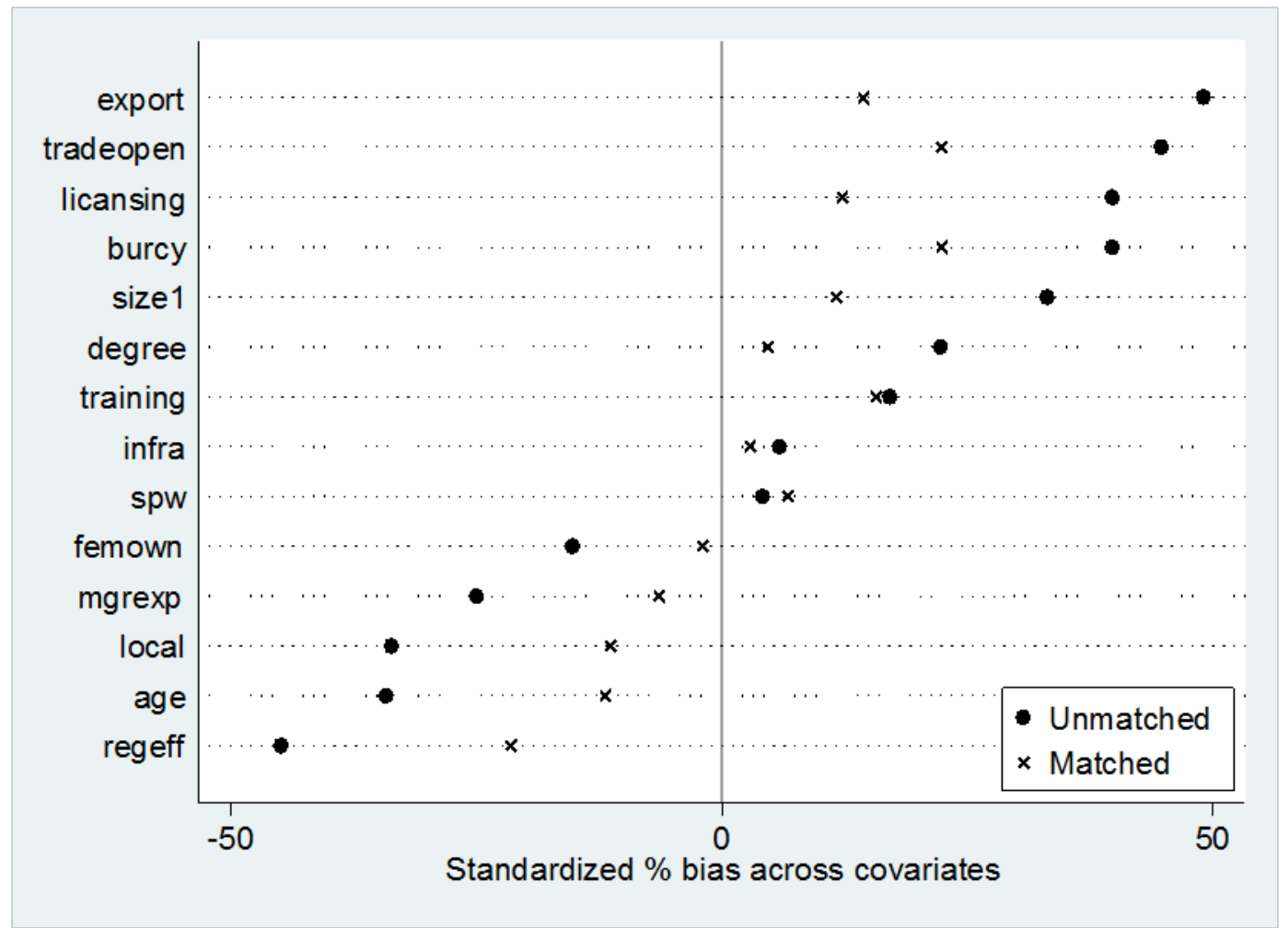

Treatment variable: burcy1

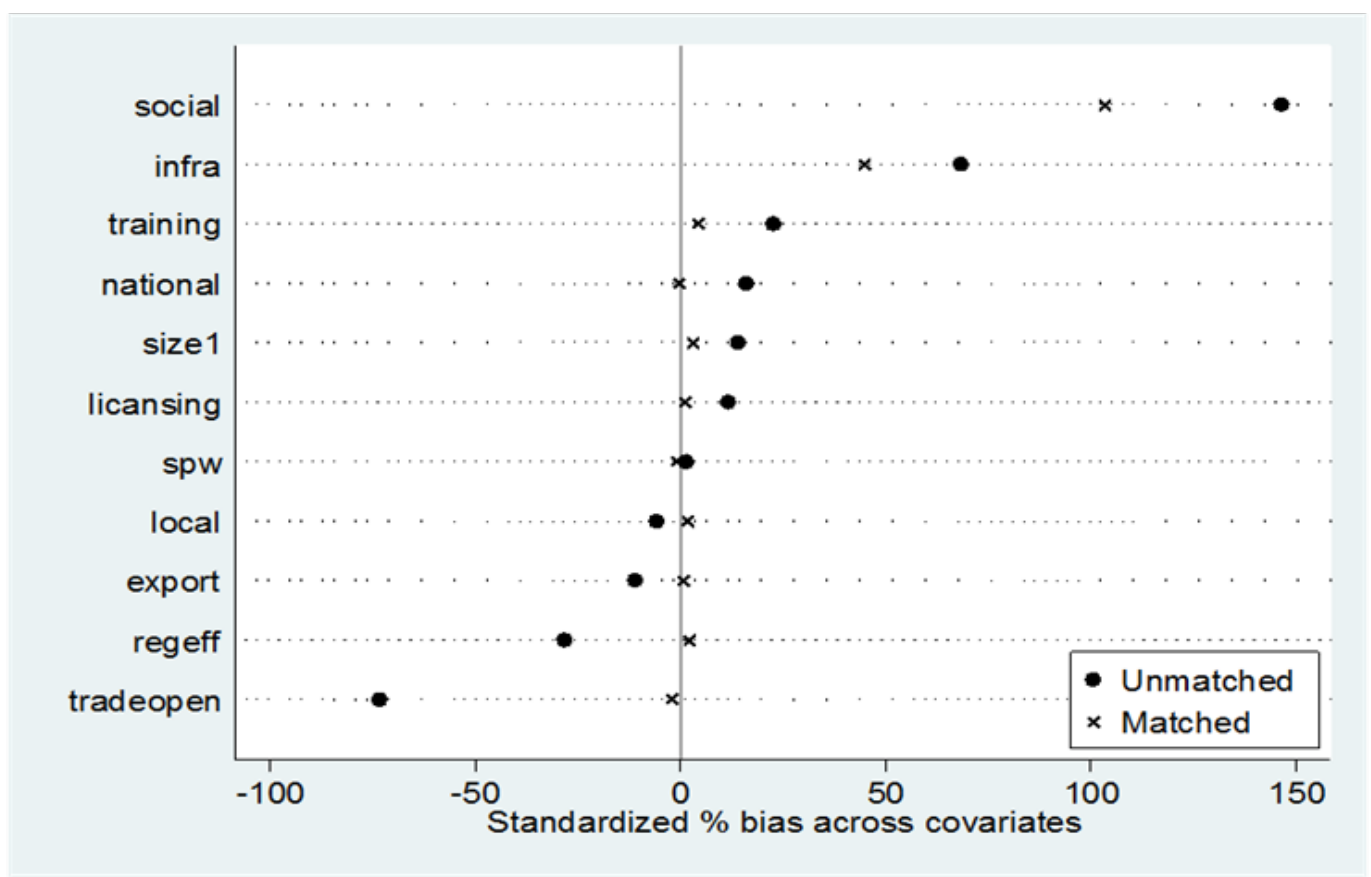


Treatment variable: govtbid

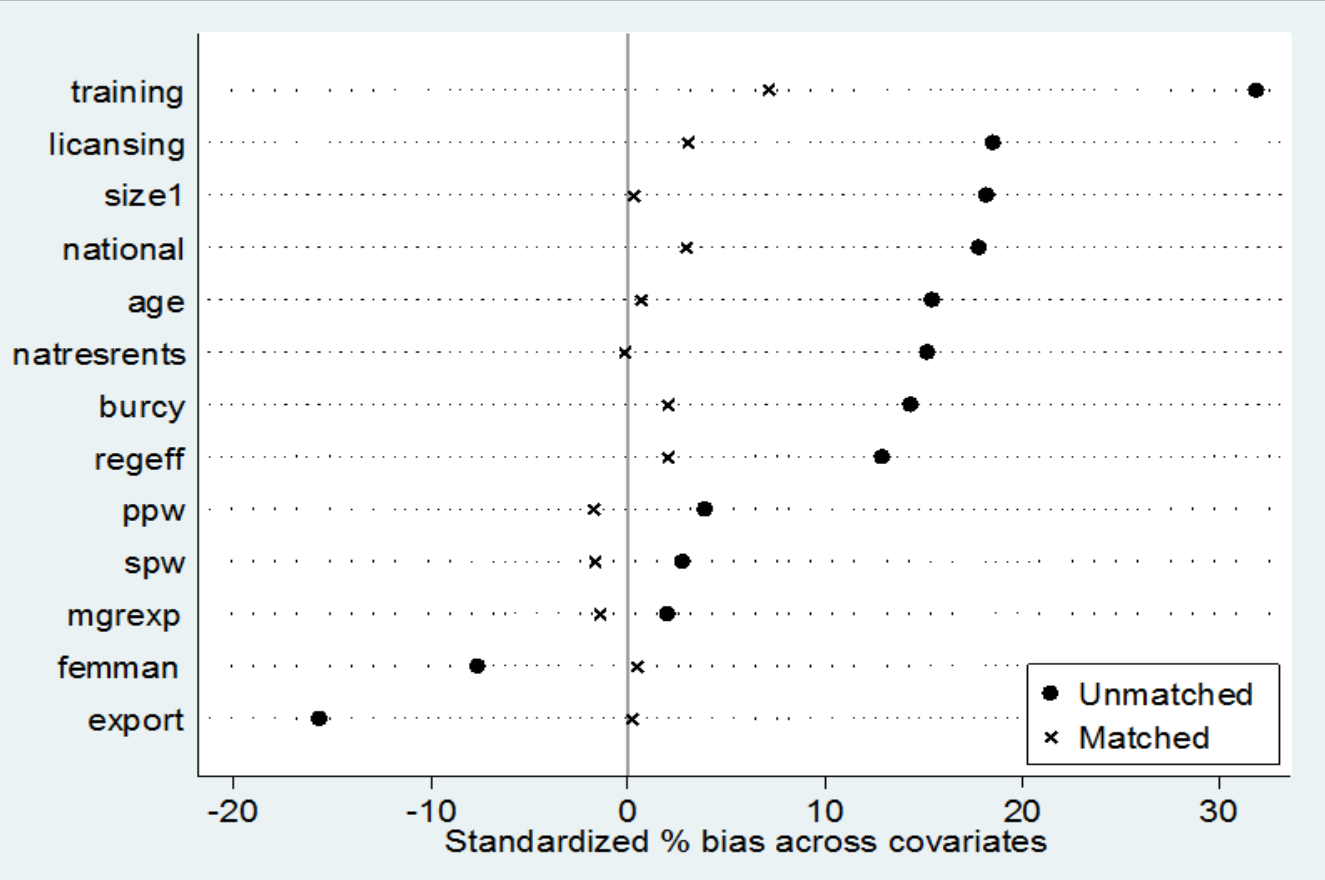

Treatment variable: polity 1

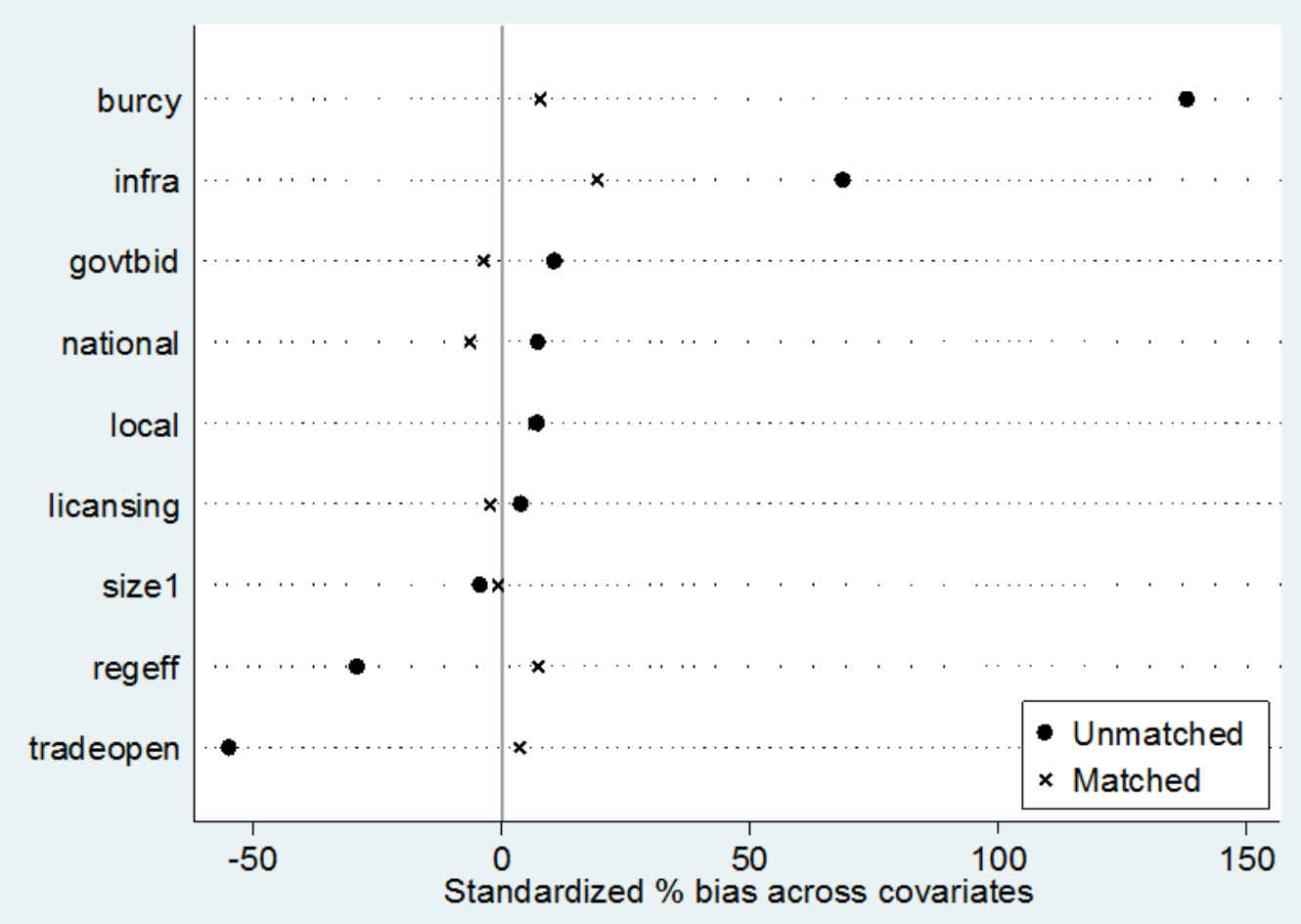


APPENDIX 7: CHECKS FOR BIAS ON OBSERVABLES - SAMPLE 2

Treatment variable: foreign 1

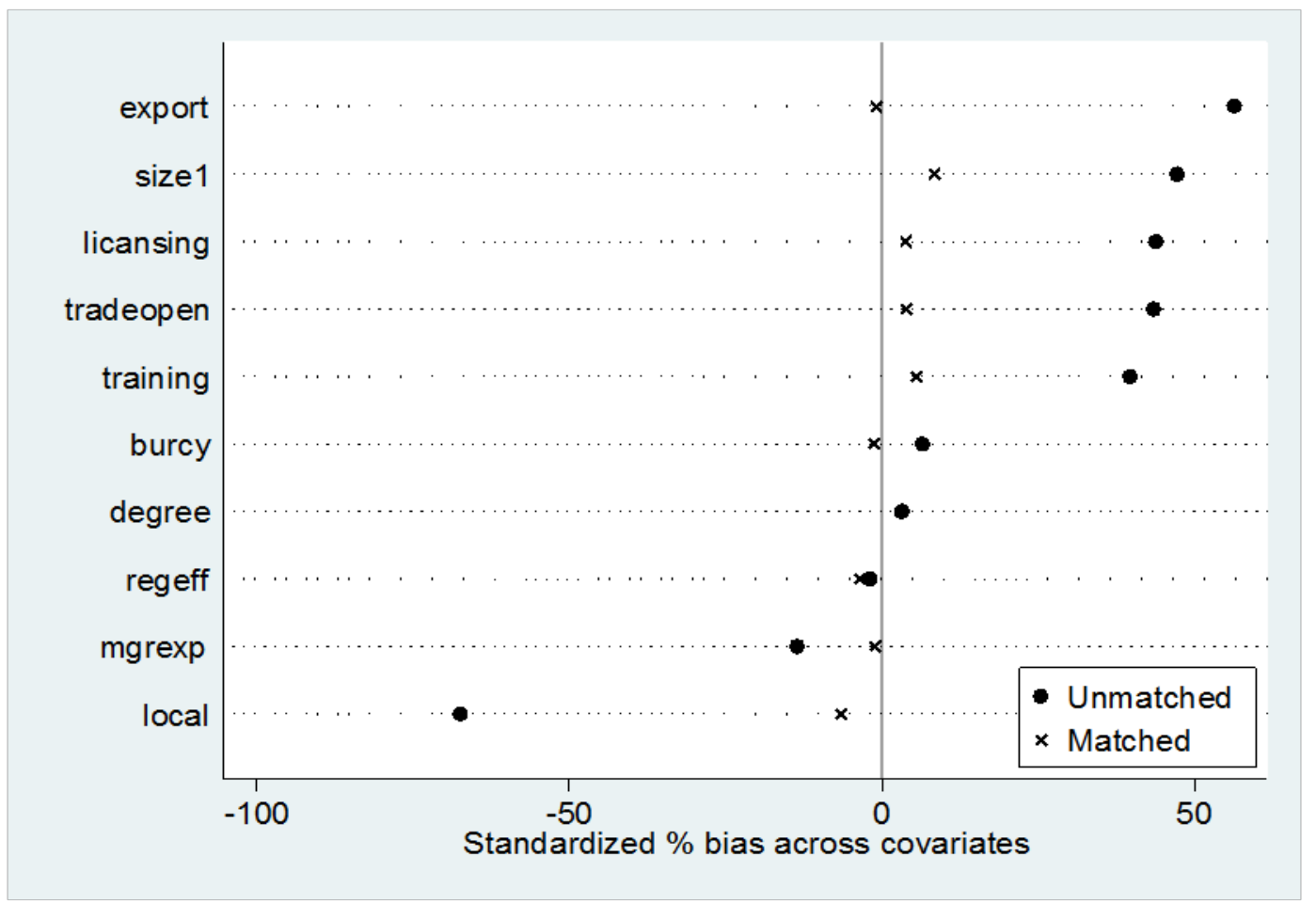

Treatment variable: foreign3

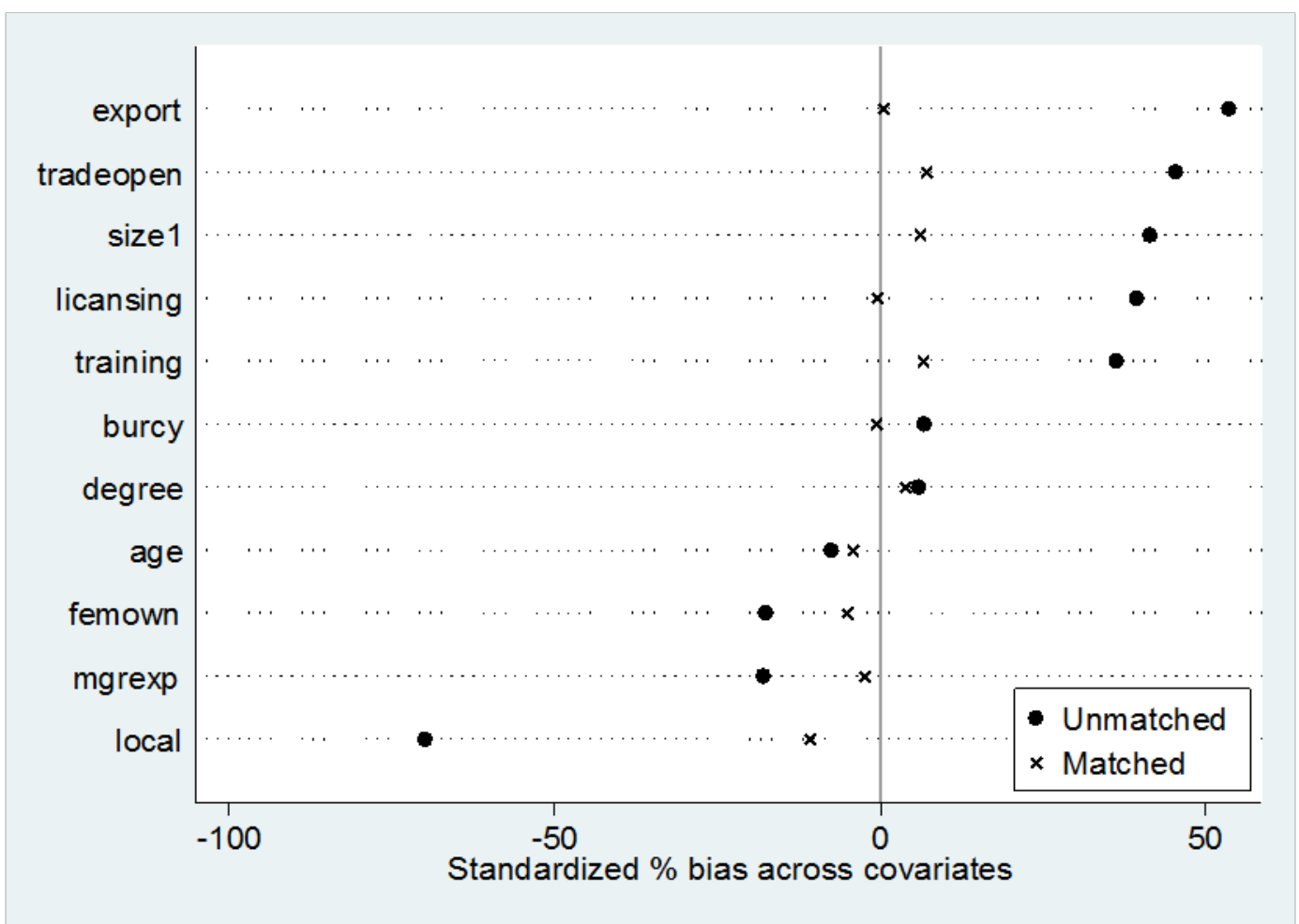


Treatment variable: jointvent

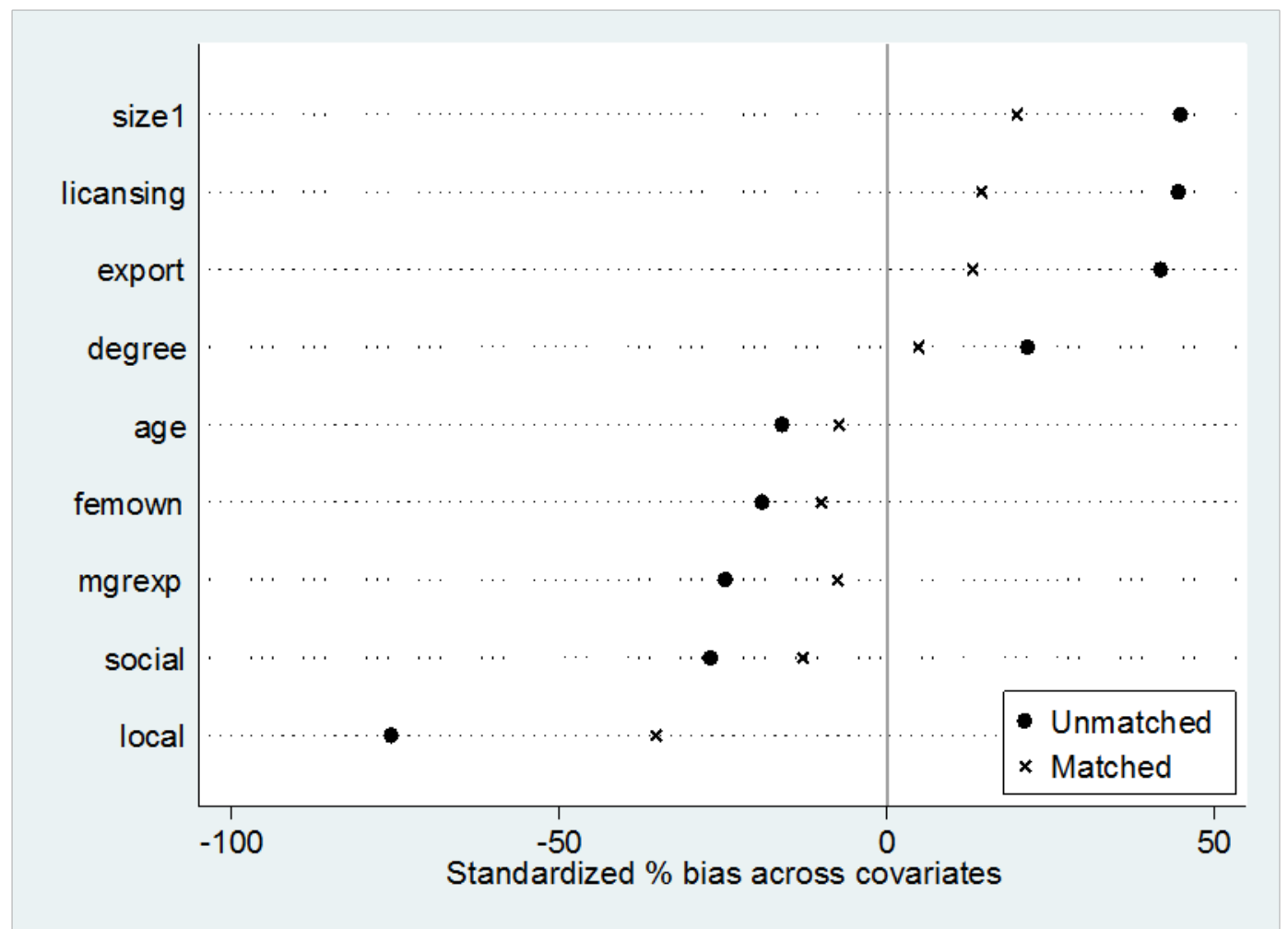

Treatment variable: burcy1

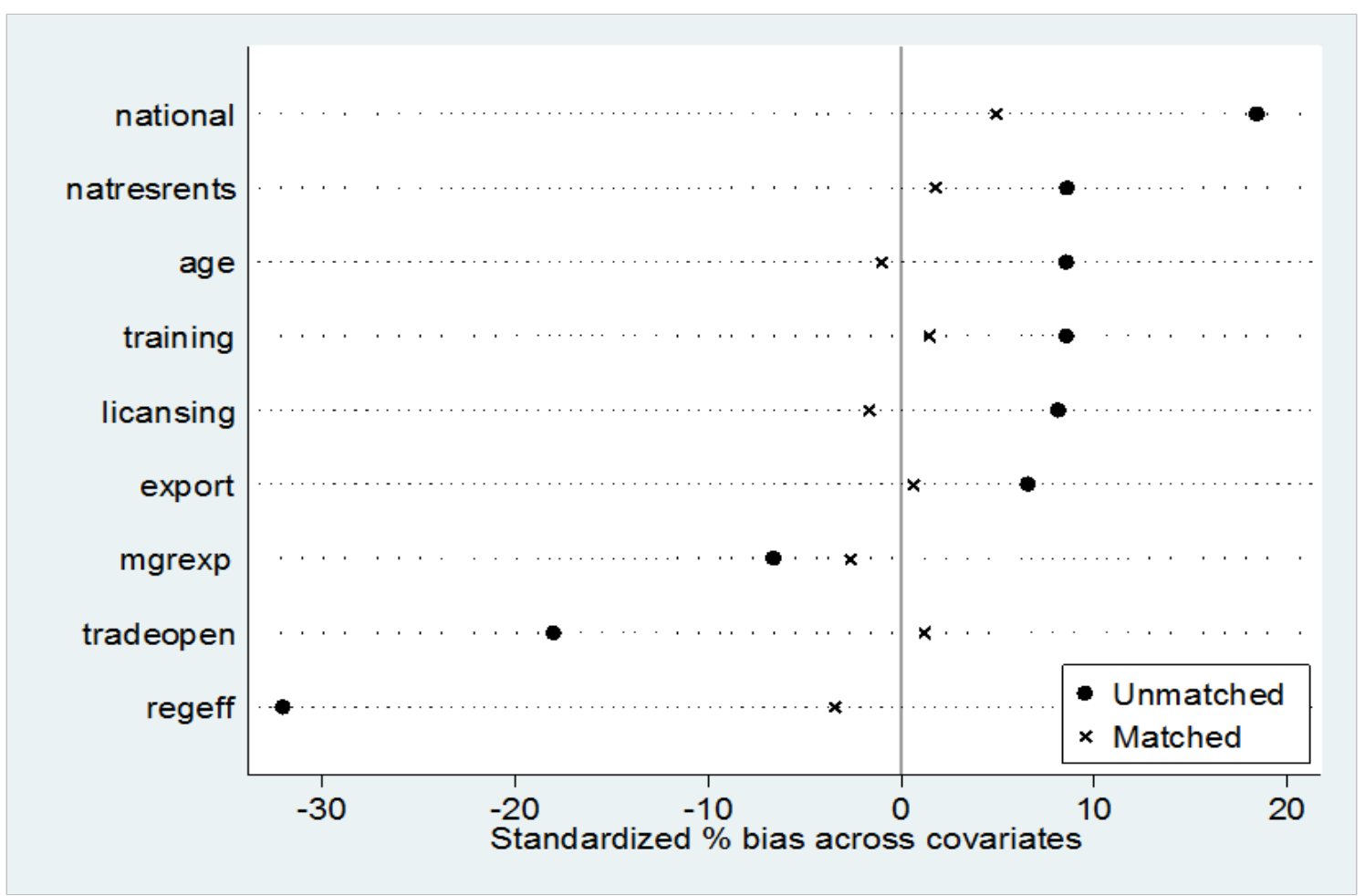


Treatment variable: govtbid

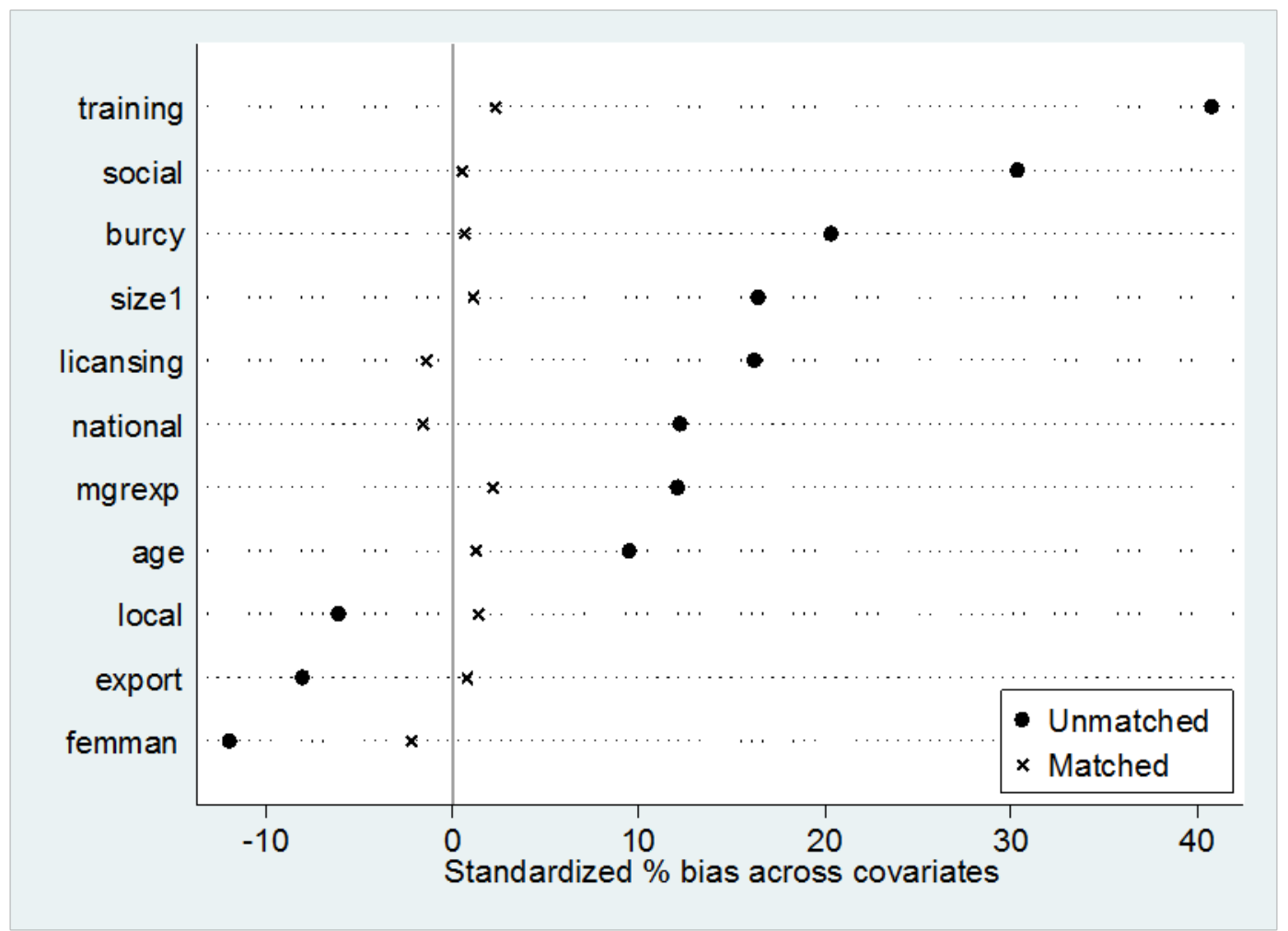

Treatment variable: polity 1

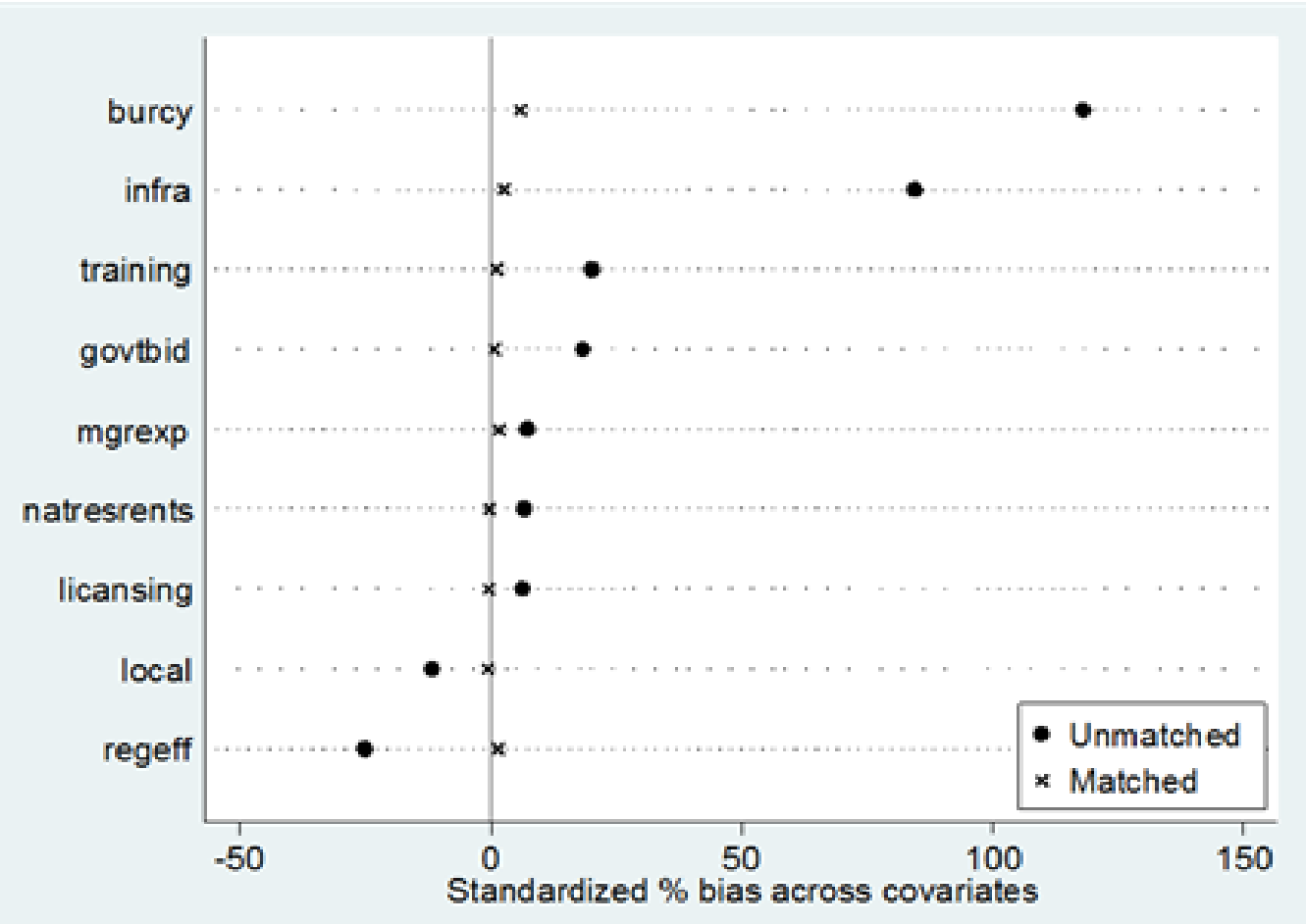

